\title{
Synthesis and characterization of thermally stable aromatic polyamides and poly (1,3,4-oxadiazole-amide)s nanoparticles containing pendant substituted bezamides
}

\author{
Hammed HAM Hassan*, Amel F Elhusseiny, Yasmeen MA Elkony and El-Sayed ME Mansour
}

\begin{abstract}
Background: The introduction of pendent bulky groups along the polymer backbone results in a less ordered polymer matrix and increases the solubility characteristics without affecting thermal properties. The inclusion of chromogenic chemical moieties in the chains can give rise to the luminescent converter material which permits the preparation of materials with potential applications. Aromatic polymers containing heterocyclic rings in the main chain are known for their high thermal resistance, good hydrolytic stability, low dielectric and tough mechanical properties. There is currently much research directed towards the discovery of new blue light-emitting polymers, with characteristics of high efficiency and high reliability. Herein, we describe the preparation of aromatic polyamides and poly (1,3,4-oxadiazole-amide)s nanoparticles with pendant structures comprised of $m$ - and p-acetoxybenzamide groups, where the acetoxybenzamide groups act as signaling units due to their fluorescent and chromogenic characteristics.

Results: Aromatic polyamides and poly(1,3,4-oxadiazole-amide)s nanoparticles with pendant structures comprised of $m$ - and $p$-acetoxybenzamide groups were successfully prepared and characterized using different analytical methods. Most polyamides were obtained as well-separated spherical nanoparticles while aramide containing pyridine produced aggregated particles attributed to the molecular self assembly via $\mathrm{H}$-bond directed organization of molecular precursors. The thermal behavior of all polymers exhibited two major thermal decompositions due to the subsequent breakage of the acetoxy group in the lateral chain and cleavage of the main amide bonds. Photoluminescence studies revealed that the blue emissions for the polyamide derived from benzidine were blue-shifted (shifted to a lower wavelength) compared to that of polyamides containing flexible linkages.
\end{abstract}

Conclusions: We report the synthesis of aromatic polyamides and poly(1,3,4-oxadiazole-amide)s nanoparticles with pendant structures comprised of $m$ - and $p$-acetoxybenzamide groups. The thermal behavior of all polymers exhibited two major decompositions due to breakage of the acetoxy group in the lateral chain and cleavage of the main amide bonds. Structure- photoluminescence correlation demonstrated an interesting connection between structural modification and optical properties. The blue emissions for the polyamide derived from benzidine, attributed to the highly conjugation system, was blue shifted with the introduction of flexible linkages. The prepared polymers dissolved in warm polar aprotic solvents. Further investigations to obtain films with reasonably good mechanical properties for different applications are in progress.

Keywords: Nanoparticles, Synthesis, Aramides, Fluorescence, SEM, Thermal analysis, Oxadiazole ring

\footnotetext{
* Correspondence: dr_hassan1960@yahoo.com

Chemistry Department, Faculty of Science, Alexandria University, P.O. Box

426-Ibrahimia, Alexandria 21321, Egypt
} 


\section{Background}

Chemical functionalization of the structure of highperformance materials, that is, aramids, expands their applicability to new and cutting-edge fields. Chemical modification of aromatic polyamides is rarely performed. Few successful examples have been published in the literature due to their insolubility and the presence of amide linkages that can undergo side reactions. Several approaches to soluble polyamides including the incorporation of flexible linkages or bulky substitutes have been developed [1]. The main concept behind all these approaches is the reduction of the packing force and the increasing of the free volume of the polymers. Methods used to improve the solubility and lower glass transition temperature of the polymers are the introduction of flexible groups, large pendent groups or polar substituents. The introduction of pendent bulky groups along the polymer backbone results in a less ordered polymer matrix increasing the solubility characteristics without affecting thermal and mechanical properties to any great extent. The design and preparation of organic functional materials can be carried out by two methods [2,3]: by synthesis of monomers containing the desired functionality or by modification of the chemical structure of a parent polymer. The latter has advantages related to the economics of the process and it opens a way for total or partial modification of the parent structure with the desired functionality while still retaining the properties of the parental compound to a degree including the characteristics of the functional groups. Thus, the inclusion of chromogenic and fluorescent chemical moieties in the lateral aromatic polyamide chains [1], can give rise to the luminescent converter (LUCO) materials, which in combination with a primary pumping source, that is, blue light-emitting diodes (LEDs), permits the preparation of LEDs with tremendous potential in lighting and backlighting applications [4-8]. In addition, if the chromogenic and fluorescent moieties include a substructure capable of interacting selectively with analytes, the variations in the chromogenic or fluorescent behavior of the material permit the preparation of chemical sensors that could be used to detect analytes using the different spectral characteristics of light emitted by hybrid LUCO/LED devices or by fine tuning the visual perception of their emitted light (color). In parallel, if the functionalization gives rise to colored host substructures, the interaction with guest analytes may also lead to color changes, which could give rise to "naked eye" colorimetric sensing materials $[9,10]$.

Heterocyclic rings have been widely incorporated into the chains of the polyamides. Generally, the heterocyclic units in the main chain and/or in the pendant structure impart excellent thermal stability with improved solubility which justifies the research efforts directed toward them [11-14]. Aromatic polymers containing 1,3,4oxadiazole rings in the main chain are well known for their high thermal resistance in oxidative atmosphere, good hydrolytic stability, low dielectric constant and tough mechanical properties [15-17]. There is currently much research directed towards the discovery of new blue light-emitting polymers, with characteristics of high efficiency and high reliability. For such a purpose poly (1,3,4-oxadioazole)s are of great interest due to electron withdrawing character of the 1,3,4-oxadiazole rings that can facilitate the injection and transport of electrons. Several different reaction pathways have been developed to prepare poly(1,3,4-oxadiazole)s [18]. The most popular synthesis involves the preparation of a precursor polyhydrazides by the reaction of a diacyl chloride or derivative with hydrazine or a dihydrazide compound. The precursor polyhydrazids are cyclized to the polyoxadiazoles by heating under vacuum or heating in a dehydrating solvent such as sulfuric acid, polyphosphoric acid, or phosphoryl chloride. A different synthetic procedure produces polyoxadiazoles in one step by the solution polymerization of a dicarboxylic acid or the corresponding nitrile, amide, or ester with hydrazine or its salt in polyphosphoric or sulfuric acid or a phosphorus pentoxide/ methanesulfonic acid mixture. In addition, aromatic polyether synthesis through aromatic nucleophilic displacement reaction has been used for the preparation of aryl ether-containing poly(1,3,4 oxadiazole)s or 1,3,4-oxadiazole-containing polyethers.

We previously succeeded to prepare aromatic polyamides nanoparticles with remarkable electrical and biomedical properties [19-23]. Herein, we describe the preparation of novel aromatic polyamides and poly (1,3,4-oxadiazole-amide)s nanoparticles with pendant structures comprised of $m$ - and $p$-acetoxybenzamide groups [11], where the acetoxybenzamide groups act as signaling units due to their fluorescent and chromogenic characteristics. These model compounds were also used to study the influence of the acetoxy group orientation on the thermal stability and photoluminescence behavior of the polymers.

\section{Experimental \\ Materials}

5-Aminoisophthalic acid, $m$-hydroxybenzoic acid, $p$-hydroxylbenzoic acid and the commercial diamines namely; $m$-phenylenediamine, $p$-phenylenediamine, 2,6-diaminopyridine, benzidine, $4,4^{\prime}$ - oxydianiline, $4,4^{\prime}$-dianilinesulfone, 4,4'-methylenedianiline and the solvents $N, N$-dimethyl acetamide (DMAc), N,N-dimethylformamide (DMF), dimethylsulfoxide (DMSO) (Alfa), methyl alcohol (Aldrich), thionylchloride (Alfa), acetic anhydride (Aldrich), hydrazine hydrate (Aldrich), acetyl chloride (Aldrich) were used as purchased without purification. 


\section{Measurements}

Melting points were determined with an electro-thermal melting point apparatus and are not corrected. Infrared spectra (IR, KBr pellets; $3 \mathrm{~mm}$ thickness) were recorded on a Perkin-Elmer Infrared Spectrophotometer (FTIR 1650). All spectra were recorded within the wave number range of $600-4000 \mathrm{~cm}^{-1}$ at $25^{\circ} \mathrm{C}$. Absorption spectra were measured with a UV $500 \mathrm{UV}$-Vis spectrometer at room temperature (rt) in DMSO with a polymer concentration of $2 \mathrm{mg} / 10 \mathrm{~mL}$. Inherent viscosities $\left(\eta_{\text {inh }}\right)$ were measured at a concentration of $0.5 \mathrm{~g} / \mathrm{dL}$ in DMSO at $30^{\circ} \mathrm{C}$ by using an Ubbelohde viscometer. Differential thermogravimetric (DTG) analyses were carried out in the temperature range from $25^{\circ} \mathrm{C}$ to $700^{\circ} \mathrm{C}$ in a steam of nitrogen atmosphere by a Shimadzu DTG $60 \mathrm{H}$ thermal analyzer. The experimental conditions were: platinum crucible, nitrogen atmosphere with a $30 \mathrm{ml} / \mathrm{min}$ flow rate and a heating rate $20^{\circ} \mathrm{C} / \mathrm{min}$. Differential scanning calorimetry (DSC-TGA) analyses were carried out using SDTQ600-V20.5-Build-15 at the Institute of Graduate Studies and Research, Alexandria University. Elemental analyses were performed at the Microanalytical Unit, Cairo University. The morphologies of polymer nanoparticles were observed by Scanning Electron Microscope (SEM) (JEOL-JSM5300), at the E-Microscope Unit; Faculty of Science, Alexandria University. The samples were sonicated in de-ionized water for $5 \mathrm{~min}$ and deposited onto carbon coated copper mesh and allowed to air-dry before the examination.

\section{Synthesis of 5-(4-acetoxybenzoylamino)isophthaloyl chloride 10}

To a $50 \mathrm{ml}$ round bottom flask were added $p$-hydroxyl benzoic acid 1 (10 g, $72.5 \mathrm{mmol}$ ) and acetic anhydride $(15 \mathrm{ml})$. The mixture was refluxed for $2 \mathrm{~h}$ and the product was crystallized from cold water. The solid was collected by filtration, washed with large amount of water and crystallized from chloroform. $p$-Acetoxybenzoic acid 3 was obtained as a white crystal in $84 \%$ yield (10.9 g); m.p. $190^{\circ} \mathrm{C}$.

p-Acetoxybenzoic acid 3 (5 g, $27.6 \mathrm{mmol})$ and thionyl chloride $(25 \mathrm{ml})$ were refluxed for $1 \mathrm{~h}$ (till complete dissolution of the starting material). The excess of thionyl chloride was removed under vacuum. The desired p-acetoxybenzoyl chloride $\mathbf{5}$ was obtained as a white solid in $83 \%$ yield ( $5.5 \mathrm{~g})$.

5- Aminoisophthalic acid 7 (5 g, $72.5 \mathrm{mmol})$ dissolved in DMA (30 ml) was well stirred and then $p$-acetoxybenzoyl chloride 5 (5.5 g, $27.6 \mathrm{mmol}$ ) was added. The mixture was stirred for $20 \mathrm{~h}$ at $\mathrm{rt}$ and then it was poured into water and filtered. The required 5-(4-acetoxybenzoylamino) isophthalic acid 8 was obtained in 95\% yield (9 g); m.p. $296^{\circ} \mathrm{C}$. IR: 3286, 3077, 2567, 1758, 1720, 1694, 1656, 1602, $1539,1505,1439,1412,1372,1334,1283,1203,1168$,
1107, 1070, 1016, 951, 914, 883, 854, 758, 694, 666, 612, 539, 502, 464.

Finely powdered diacid 8 (6 g, $17.5 \mathrm{mmol})$ was mixed with thionyl chloride $(25 \mathrm{ml})$. The mixture was refluxed for $1 \mathrm{~h}$ and then distilled off. The desired 5-(4-acetoxybenzoylamino)isophthaloyl chloride $\mathbf{1 0}$ was obtained in quantitative yield (7.2 g); m.p. $126^{\circ} \mathrm{C}$ and it was used as such in the following steps.

\section{Synthesis of 5-(3-acetoxybenzoylamino)isophthaloyl chloride 11}

$m$-Acetoxybenzoic acid 4 was obtained starting from $m$ hydroxylbenzoic acid 2 as a white crystal in $78 \%$ yield; m.p. $130^{\circ} \mathrm{C}$, following the above described method for preparation of compound 3. $m$-Acetoxybenzoyl chloride 6 was obtained in $83 \%$ yield starting from compound 4 following the above described method for preparation of compound 5.

5-(3-Acetoxybenzoylamino)isophthalic acid 9 was obtained in $89 \%$ yield $(8.4 \mathrm{~g})$ as a white solid starting from coupling reaction of 5 -aminoisophthalic acid 7 and $m$-acetoxybenzoyl chloride $\mathbf{6}$ following the above described method for preparation of compound 8. IR $\left(\mathrm{v}, \mathrm{cm}^{-1}\right): 3299,2987,2830,2640,2569,1761,1690$, $1656,1588,1538,1487,1446,1408,1373,1334,1277$, $1214,1135,1105,1078,1016,1001,957,930,914,836$, 809, 759, 693, 679, 614, 533, 510, 470, 440.

Finely powdered diacid 9 (6 g, $17.5 \mathrm{mmol})$ was mixed with thionyl chloride $(25 \mathrm{ml})$ and the mixture was refluxed for $1 \mathrm{~h}$. The mixture was distilled off and the obtained solid of 5-(3-acetoxybenzoylamino)isophthaloyl chloride 11 was used as such without further purification. IR: 3901, 3852, 3837, 3292, 3078, 2922, 2850, 1952, $1762,1653,1586,1540,1482,1450,1370,1335,1294$, 1199, 1143, 1016, 999, 948, 903, 877, 833, 805, 783, 684, $607,528,494,470$.

\section{Polymer synthesis by low temperature solution polycondensation (General method)}

In a dry round flask, the appropriate diamine $(10.0 \mathrm{mmol})$ and 5-(4-acetoxybenzoylamino)isophthaloyl chloride $\mathbf{1 1}$ $(10.0 \mathrm{mmol})$ in $15 \mathrm{ml}$ of DMA was strongly stirred at $0^{\circ} \mathrm{C}$ for $30 \mathrm{~min}$. then at $\mathrm{rt}$ for $10 \mathrm{~h}$. The solution was poured into cooled water and the produced polymer was collected by filtration and washed subsequently with water, ethanol and water again and then dried in a vacuum oven at $60^{\circ} \mathrm{C}$.

Reaction of 5-(4-acetoxybenzoylamino)isophthaloyl chloride 10 with p-phenylenediamine: Preparation of Polymer 12

Yield: $62.0 \%$, m.p. $>300^{\circ} \mathrm{C}, \eta_{\text {inh }}=0.575 \mathrm{dL} / \mathrm{g}$. IR $\left(\mathrm{v}, \mathrm{cm}^{-1}\right)$ : 3289 ( $\left.\mathrm{N}-\mathrm{H}_{\text {str }}\right), 3078,2580,1715$ (CO ester), 1657 (CO amide), 1601 (aromatic $\mathrm{C}-\mathrm{H}_{\text {str }}, 1548,1506,1430,1371$, 1332, 1281, 1203, 1167, 1107, 1016, 951, 914, 882, 855, 
758, 693, 668, 612, 518. Elemental analysis calculated for $12\left(\mathrm{C}_{23} \mathrm{H}_{19} \mathrm{~N}_{3} \mathrm{O}_{6}\right)_{\mathrm{n}}: \mathrm{C}, 63.74 ; \mathrm{H}, 4.38 ; \mathrm{N}, 9.69$; Found: $\mathrm{C}$, 63.29; H, 4.02; N, 9.40.

Reaction of 5-(3-acetoxybenzoylamino)isophthaloyl chloride 11 with p-phenylenediamine: Preparation of Polymer 13

Yield: $71.4 \%$, m.p. $>300^{\circ} \mathrm{C}, \eta_{\text {inh }}=0.575 \mathrm{dL} / \mathrm{g}$. IR $\left(\mathrm{v}, \mathrm{cm}^{-1}\right)$ : 3897, 3863, 3848, 3832, 3814, 3794, 3743, 3729, 3705, $3684,3664,3641,3290,3072,2921,2355,1902,1762$, $1737,1659,1599,1552,1514,1445,1403,1370,1313$, 1218, 1110, 1015, 978, 900, 832, 748, 680, 599. Elemental analysis calculated for $13,\left(\mathrm{C}_{23} \mathrm{H}_{19} \mathrm{~N}_{3} \mathrm{O}_{6}\right)_{\mathrm{n}}$ : C, 63.74; $\mathrm{H}$, 4.38; N, 9.69; Found: C, 63.39; H, 4.81; N, 9.28.

Reaction of 5-(4-acetoxybenzoylamino)isophthaloyl chloride 10 with m-phenylenediamine: Preparation of Polymer 14

Yield: $62.0 \%$, m.p. $>300^{\circ} \mathrm{C}, \eta_{\text {inh }}=0.672 \mathrm{dL} / \mathrm{g}$. IR $\left(\mathrm{v}, \mathrm{cm}^{-1}\right)$ : $3303\left(\mathrm{~N}-\mathrm{H}_{\text {str }}\right), 1748,1659$ (C= O amide), 1603 (aromatic C-H $\left.{ }_{\text {str }}\right), 1542,1488,1445,1369,1336,1302,1201,1166$, $1109,1015,915,884,855,784,757,687,614$, 543. Elemental analysis calculated for $14\left(\mathrm{C}_{23} \mathrm{H}_{19} \mathrm{~N}_{3} \mathrm{O}_{6}\right)_{\mathrm{n}}$ : C, 63.74; $\mathrm{H}$, 4.38; N, 9.69. Found: C, 63.81; H, 4.77; N, 9.75.

Reaction of 5-(3-acetoxybenzoylamino)isophthaloyl chloride 11 with m-phenylenediamine: Preparation of Polymer 15 Yield: $60 \%$, m.p. $>300^{\circ} \mathrm{C}, \eta_{\text {inh }}=0.445 \mathrm{dL} / \mathrm{g}$. IR $\left(\mathrm{v}, \mathrm{cm}^{-1}\right)$ : 3686, 3299, 3078, 2923, 2358, 1760, 1738, 1661, 1604, $1546,1485,1443,1369,1333,1296,1217,1015,886$, $830,784,747,685,601,533$. Elemental analysis calculated for $15\left(\mathrm{C}_{23} \mathrm{H}_{19} \mathrm{~N}_{3} \mathrm{O}_{6}\right)_{\mathrm{n}}$ : C, 63.74; $\mathrm{H}, 4.38 ; \mathrm{N}, 9.69$; Found: C, 64.11; H, 4.56; N, 9.83.

Reaction of 5-(4-acetoxybenzoylamino)isophthaloyl chloride 10 with 2,6-diaminopyridine: Preparation of Polymer 16 Yield: $50 \%$, m.p. $>300^{\circ} \mathrm{C}, \eta_{\mathrm{inh}}=0.765 \mathrm{dL} / \mathrm{g}$. IR $\left(\mathrm{v}, \mathrm{cm}^{-1}\right)$ : 3351, 1658, 1604, 1552, 1505, 1447, 1370, 1333, 1281, $1201,1165,1015,912,853,800,759,670,611$. Elemental analysis calculated for $16\left(\mathrm{C}_{22} \mathrm{H}_{18} \mathrm{~N}_{4} \mathrm{O}_{6}\right)_{\mathrm{n}}$ : C, 60.82; $\mathrm{H}$, 4.14; N, 12.90; Found: C, 60.42; H, 3.88; N, 12.61.

Reaction of 5-(3-acetoxybenzoylamino)isophthaloyl chloride 11 with 2,6-diaminopyridine: Preparation of Polymer 17

Yield: $50 \%$, m.p. $>300^{\circ} \mathrm{C}, \eta_{\text {inh }}=0.575 \mathrm{dL} / \mathrm{g}$. IR $\left(\mathrm{v}, \mathrm{cm}^{-1}\right)$ : 3986, 3849, 3831, 3813, 3792, 3702, 3302, 3070, 2921, 2357, 1762, 1735, 1659, 1595, 1530, 1445, 1410, 1370, $1321,1214,1112,1017,904,810,750,682,604,531$. Elemental analysis calculated for $17\left(\mathrm{C}_{22} \mathrm{H}_{18} \mathrm{~N}_{4} \mathrm{O}_{6}\right)_{\mathrm{n}}$ : C, 60.82; H, 4.14; N, 12.90; Found: C, 60.54; H, 4.53; N, 13.27.

Reaction of 5-(4-acetoxybenzoylamino)isophthaloyl chloride 10 with benzidine: Preparation of Polymer 18

Yield: $95 \%$, m.p. $>300^{\circ} \mathrm{C}, \eta_{\mathrm{inh}}=0.575 \mathrm{dL} / \mathrm{g}$. IR $\left(\mathrm{v}, \mathrm{cm}^{-1}\right)$ : IR: 3434, 1756, 1618, 1503, 1403, 1319, 1244, 1195, 1166, 1060, 1018, 912, 851, 821, 742, 674, 595, 517, 479.
Elemental analysis calculated for $18\left(\mathrm{C}_{29} \mathrm{H}_{23} \mathrm{~N}_{3} \mathrm{O}_{6}\right)_{\mathrm{n}}$ : 68.36; H, 4.51; N, 8.25. Found: C, 67.98; H, 4.91; N, 7.89.

Reaction of 5-(3-acetoxybenzoylamino)isophthaloyl chloride 11 with benzidine: Preparation of Polymer 19

Yield: $83 \%$, m.p. $>300^{\circ} \mathrm{C}$. IR (v, $\mathrm{cm}^{-1}$ ): 3639, 3301, 3071, 2924, 2357, 1903, 1762, 1735, 1661, 1592, 1501, 1445, 1415, 1369, 1322, 1293, 1213, 1112, 1005, 900, 819, 747, 680, 599, 517. Elemental analysis for $19\left(\mathrm{C}_{29} \mathrm{H}_{23} \mathrm{~N}_{3} \mathrm{O}_{6}\right)_{\mathrm{n}}$ : C, 68.36; $\mathrm{H}$, 4.51; N, 8.25; Found: C, 68.72; H, 4.89; N, 7.99.

Reaction of 5-(4-acetoxybenzoylamino)isophthaloyl chloride 10 with 4,4'-oxydianiline: Preparation of Polymer 20

Yield: $51 \%$, m.p. $>300^{\circ} \mathrm{C}, \eta_{\text {inh }}=0.472 \mathrm{dL} / \mathrm{g}$. IR $\left(\mathrm{v}, \mathrm{cm}^{-1}\right)$ : 3303, 3070, 1748, 1657, 1600, 1539, 1499, 1445, 1408, 1370, 1310, 1285, 1230, 1166, 1106, 1014, 960, 914, 876, 832, 757, 702, 613, 515. Elemental analysis calculated for $20\left(\mathrm{C}_{29} \mathrm{H}_{23} \mathrm{~N}_{3} \mathrm{O}_{7}\right)_{\mathrm{n}}$ : C, 66.28; H, 4.38; N, 8.00; Found: $\mathrm{C}$, 66.72; H, 4.66; N, 8.33.

Reaction of 5-(3-acetoxybenzoylamino)isophthaloyl chloride 11 with 4,4'-oxydianiline: Preparation of Polymer 21

Yield: $88 \%$, m.p. $>300^{\circ} \mathrm{C}, \eta_{\text {inh }}=0.448 \mathrm{dL} / \mathrm{g}$. IR $\left(\mathrm{u}, \mathrm{cm}^{-1}\right)$ : 3303, 3070, 2926, 2854, 2359, 2337, 2075, 1883, 1763, $1740,1661,1599,1535,1499,1444,1409,1369,1297$, 1230, 1106, 1043, 1014, 945, 876, 831, 747, 703, 682, 598, 513. Elemental analysis calculated for $21\left(\mathrm{C}_{29} \mathrm{H}_{23} \mathrm{~N}_{3} \mathrm{O}_{7}\right)_{n}$ : C, 66.28; H, 4.38; N, 8.00; Found: C, 65.99; H, 4.13; N, 8.38.

Reaction of 5-(3-acetoxybenzoylamino)isophthaloyl chloride 11 with 4,4'-methylenedianiline: Preparation of Polymer 23 Yield: $71 \%$, m.p. $>300^{\circ} \mathrm{C}, \eta_{\text {inh }}=0.419 \mathrm{dL} / \mathrm{g}$. IR $\left(\mathrm{v}, \mathrm{cm}^{-1}\right)$ : 3986, 3849, 3831, 3813, 3792, 3702, 3302, 3070, 2921, 2357, 1762, 1735, 1659, 1595, 1530, 1445, 1410, 1370, 1321, 1214, 1112, 1017, 904, 810, 750, 682, 604, 531, 511. Elemental analysis calculated for $23\left(\mathrm{C}_{30} \mathrm{H}_{25} \mathrm{~N}_{3} \mathrm{O}_{6}\right)_{\mathrm{n}}$ : C, 68.83; H, 4.78; N, 8.03; Found: C, 68.46; H, 5.02; N, 7.44.

Reaction of 5-(4-acetoxybenzoylamino)isophthaloyl chloride 10 with 4,4'-diaminodiphenylsulphone: Preparation of polymer 24

Yield: $51 \%$, m.p. $>300^{\circ} \mathrm{C}, \eta_{\text {inh }}=0.575 \mathrm{dL} / \mathrm{g} . \mathrm{IR}\left(\mathrm{v}, \mathrm{cm}^{-1}\right)$ : 3367, 3103, 1919, 1749, 1667, 1592, 1527, 1445, 1400, $1369,1317,1252,1202,1166,1148,1105,1072,1015$, 956, 914, 835, 755, 718, 691, 629, 574, 554. Elemental analysis calculated for $24\left(\mathrm{C}_{29} \mathrm{H}_{23} \mathrm{~N}_{3} \mathrm{O}_{8} \mathrm{~S}\right)_{\mathrm{n}}$ : C, 60.73; $\mathrm{H}$, 4.01; N, 7.32; Found: C, 61.09; H, 4.32; N, 7.71.

Reaction of 5-(3-acetoxybenzoylamino)isophthaloyl chloride 11 with 4,4'-diaminodiphenylsulphone: Preparation of polymer 25

Yield: $53 \%$, m.p. $>300^{\circ} \mathrm{C}, \eta_{\text {inh }}=0.445 \mathrm{dL} / \mathrm{g} . \mathrm{IR}\left(\mathrm{v}, \mathrm{cm}^{-1}\right)$ : 3473, 3361, 3102, 2925, 2359, 2338, 1904, 1763, 1738, $1668,1591,1529,1445,1400,1369,1318,1218,1148$, 


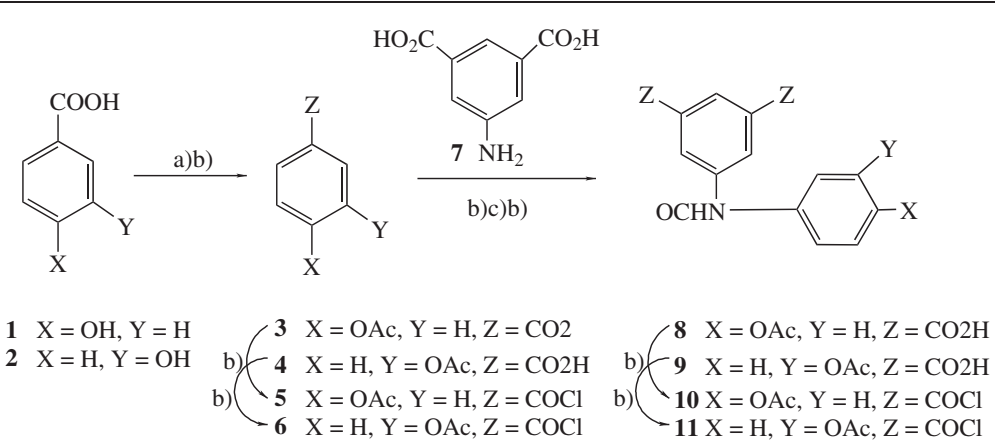

key: a) Ac O, reflux, 2h; b) SOCl, reflux, 1h; c) DMA then 7

Scheme 1 Preparation of 5-(4-acetoxybenzamido)isophthaloyl chloride 10 and 5-(3-acetoxybenzamido)isophthaloyl chloride 11.

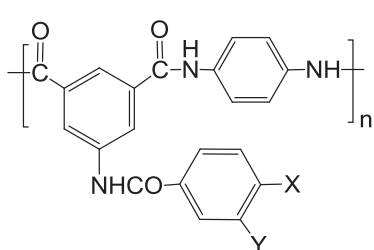

$12 \mathrm{X}=\mathrm{OAc}, \mathrm{Y}=\mathrm{H}$

$13 \mathrm{X}=\mathrm{H}, \mathrm{Y}=\mathrm{OAc}$

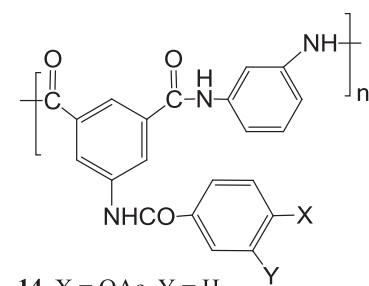

$14 \mathrm{X}=\mathrm{OAc}, \mathrm{Y}=\mathrm{H}$

$15 \mathrm{X}=\mathrm{H}, \mathrm{Y}=\mathrm{OAc}$

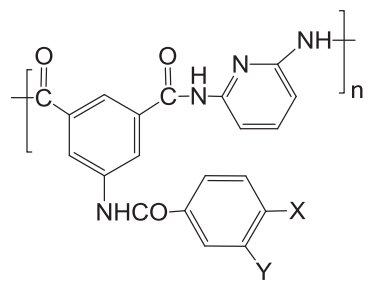

$16 \mathrm{X}=\mathrm{OAc}, \mathrm{Y}=\mathrm{H}$

$17 \mathrm{X}=\mathrm{H}, \mathrm{Y}=\mathrm{OAc}$

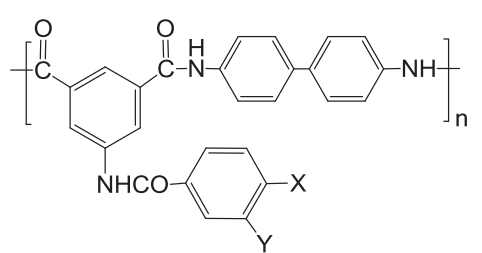

$18 \mathrm{X}=\mathrm{OAc}, \mathrm{Y}=\mathrm{H}$

$19 \mathrm{X}=\mathrm{H}, \mathrm{Y}=\mathrm{OAc}$

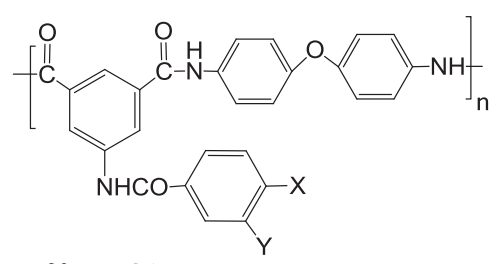

$20 \mathrm{X}=\mathrm{OAc}, \mathrm{Y}=\mathrm{H}$

$21 \mathrm{X}=\mathrm{H}, \mathrm{Y}=\mathrm{OAc}$

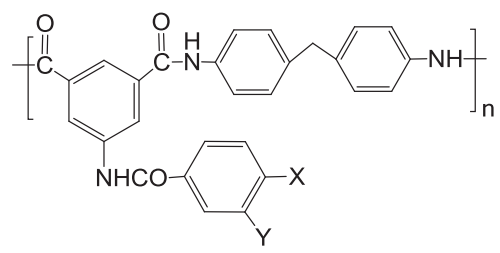

$22 \mathrm{X}=\mathrm{OAc}, \mathrm{Y}=\mathrm{H}$

$23 \mathrm{X}=\mathrm{H}, \mathrm{Y}=\mathrm{OAc}$

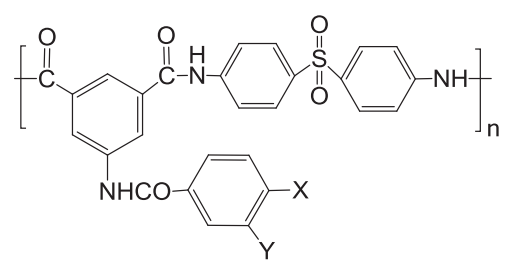

$24 \mathrm{X}=\mathrm{OAc}, \mathrm{Y}=\mathrm{H}$

$25 \mathrm{X}=\mathrm{H}, \mathrm{Y}=\mathrm{OAc}$

Figure 1 Chemical Structures of the prepared polyamides 12-25. 


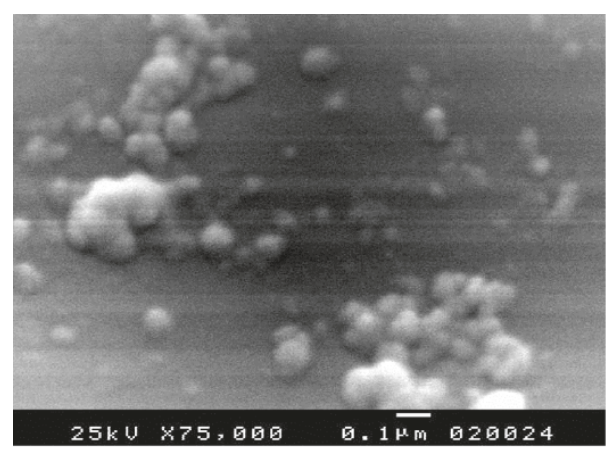

12

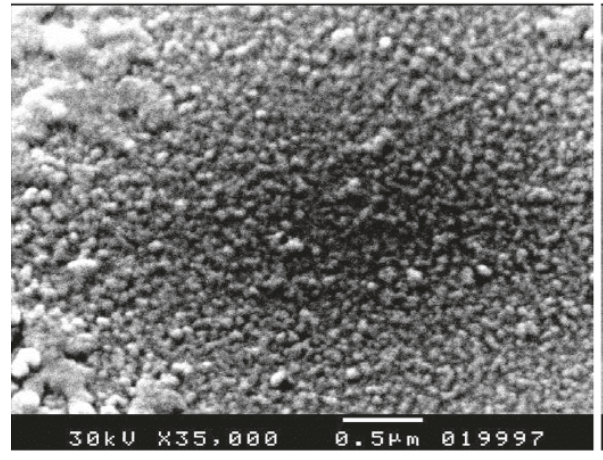

16

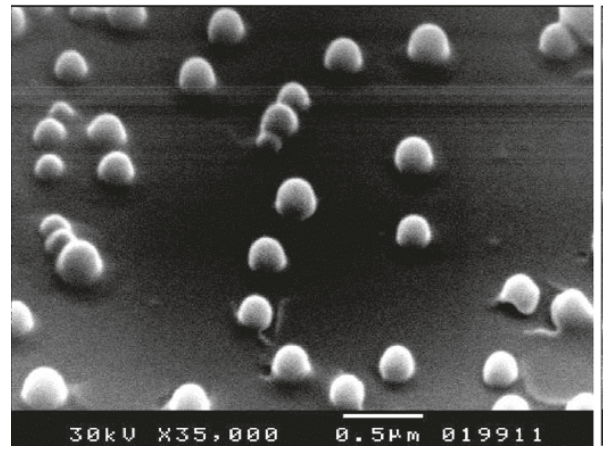

20

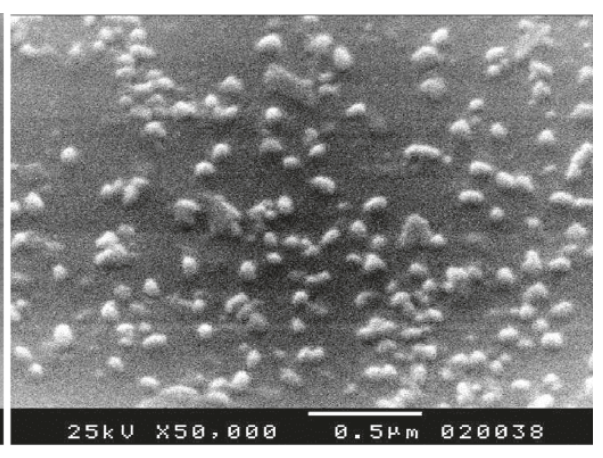

14
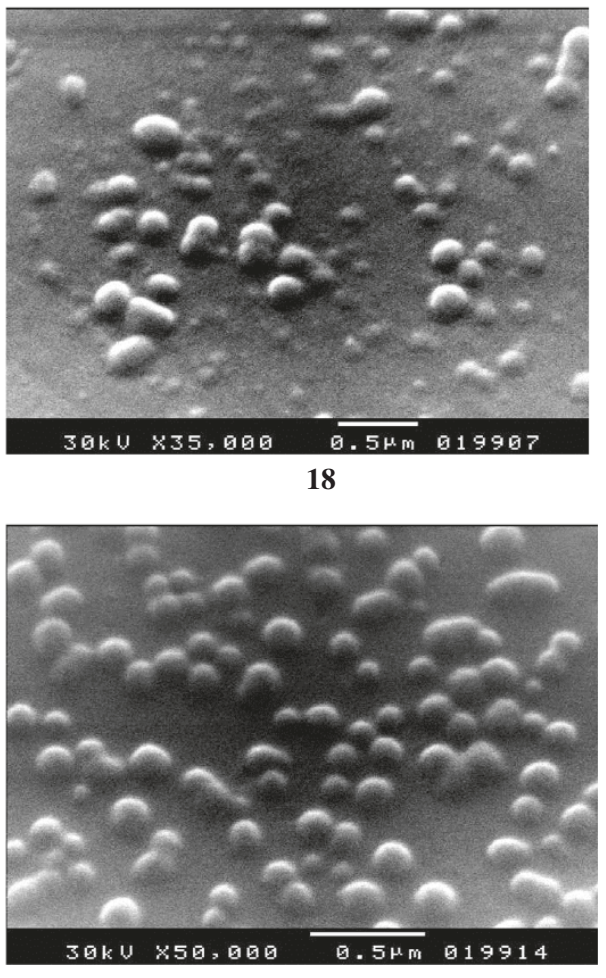

24

Figure 2 SEM images of the aramides nanoparticles 12, 14, 16, 18, 20 and 24.

1105, 1072, 1014, 943, 902, 835, 749, 719, 688, 628, 591, 554. Elemental analysis calculated for $25\left(\mathrm{C}_{29} \mathrm{H}_{23} \mathrm{~N}_{3} \mathrm{O}_{8} \mathrm{~S}\right)_{\mathrm{n}}$ : C, 60.73; H, 4.01; N, 7.32; Found: C, 60.46; H, 3.87; N, 7.64.

Synthesis of 5-(4-acetoxybenzoylamino)isophthalohydrazide 28 and 5-(3-acetoxybenzoylamino)isophthalohydrazide 29 (General method)

In a dry flask, 5-(4-acetoxybenzoylamino)isophthalic acid 8 (1 g, $2.9 \mathrm{mmol})$ dissolved in methanol $(10 \mathrm{ml})$ was mixed with acetyl chloride $(4 \mathrm{ml})$ and the mixture was refluxed for $3 \mathrm{~h}$. the solvent was then removed under vacuum to furnish methyl 5-(4-acetoxybenzoylamino) isophthalate 26 as a white solid; m.p. $230^{\circ} \mathrm{C}$. It was used as such in the next step. IR $\left(\mathrm{v} \mathrm{cm}^{-1}\right): 4016,3894,3848$, $3831,3813,3793,3726,3702,3685,3665,3641,3389$, 3324, 3198, 2950, 2353, 1909, 1719, 1706, 1649, 1605, $1551,1513,1436,1352,1284,1255,1171,1104,1005$, $907,873,845,758,719,700,672,621,586,550,515$, $481,456$.

In a similar manner, methyl 5-(3-acetoxybenzoylamino) isophthalate 27 was prepared in quantitative yield from 5(3-acetoxybenzoylamino)isophthalic acid 9; m.p. $130^{\circ} \mathrm{C}$. IR $\left(\mathrm{v} \mathrm{cm}^{-1}\right): 4069,3392,3365,3072,2951,2804,2575,1962$, $1717,1646,1585,1550,1491,1437,1342,1293,1250$, 1213, 1122, 1100, 992, 928, 903, 875, 836, 806, 793, 753,721, 679, 596, 568, 539, 513. 


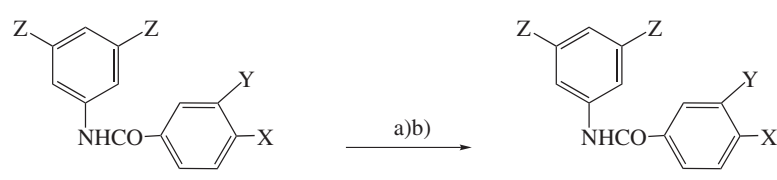

$8 \mathrm{X}=\mathrm{OAc}, \mathrm{Y}=\mathrm{H}, \mathrm{Z}=\mathrm{CO}_{2} \mathrm{H}$ $9 \mathrm{X}=\mathrm{H}, \mathrm{Y}=\mathrm{OAc}, \mathrm{Z}=\mathrm{CO}_{2} \mathrm{H}$

$26 \mathrm{X}=\mathrm{OAc}, \mathrm{Y}=\mathrm{H}, \mathrm{Z}=\mathrm{CO}_{2} \mathrm{CH}_{3}$

$27 \mathrm{X}=\mathrm{H}, \mathrm{Y}=\mathrm{OAc}, \mathrm{Z}=\mathrm{CO}_{2} \mathrm{CH}_{3}$

$28 \mathrm{X}=\mathrm{OAc}, \mathrm{Y}=\mathrm{H}, \mathrm{Z}=\mathrm{CO}_{2} \mathrm{NHNH}_{2}$

$29 \mathrm{X}=\mathrm{H}, \mathrm{Y}=\mathrm{OAc}, \mathrm{Z}=\mathrm{CO}_{2} \mathrm{NHNH}_{2}$
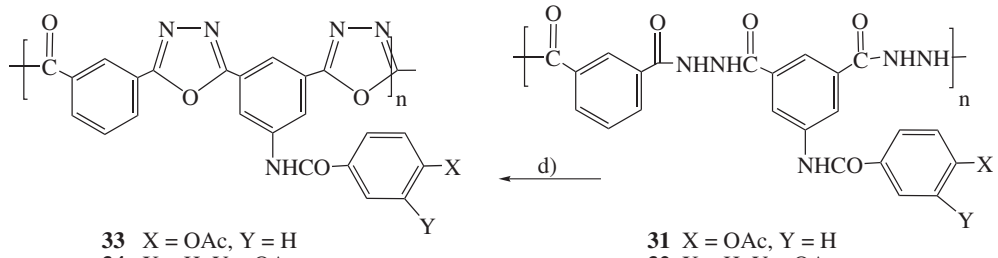

$34 \mathrm{X}=\mathrm{H}, \mathrm{Y}=\mathrm{OAc}$<smiles>O=C(Cl)c1cccc(C(=O)Cl)c1</smiles>

$32 \mathrm{X}=\mathrm{H}, \mathrm{Y}=\mathrm{OAc}$

Scheme 2 Synthetic pathways toward the hydrazide polymers 31, 32 and poly(1,3,4- oxadiazole-amide)s 33, 34.

Methyl 5-(4-acetoxybenzoylamino)isophthalate 26 (1.1 g, $2.6 \mathrm{mmol}$ ) dissolved in $10 \mathrm{ml} \mathrm{MeOH}$ was treated with hydrazine hydrate $(1.0 \mathrm{ml})$ and the mixture was refluxed for $2 \mathrm{~h}$. Solvents and volatiles were removed under vacuum and the titled compound $\mathbf{2 8}$ was obtained as white solid; m.p. $250^{\circ} \mathrm{C}$. IR $\left(\mathrm{cm}^{-1}\right)$ : 3303, 2828, 2697, 2624, 2517, 2354, $1654,1591,1554,1512,1428,1357,1309,1253,1183,1118$, 1007, 954, 891, 840, 737, 684, 592, 546, 484.

In a similar method, 5-(3-acetoxybenzoylamino)isophthalohydrazide 29 was prepared in quantitative yield from methyl 5-(3-acetoxybenzoylamino)isophthalate 27; m.p. $150^{\circ} \mathrm{C}$. IR $\left(\mathrm{cm}^{-1}\right): 3454,3371,3254,3091,3012,2959,2851,2358$, $1935,1719,1647,1602,1442,1365,1253,1104,1004,942$, $893,867,788,756,723,668,577,539$.

\section{Synthesis of poly 4-((3-(2-(3-acetylbenzoyl) hydrazinecarbonyl)-5-(2-methyl hydrazinecarbonyl)phenyl) carbamoyl)phenyl acetate 31 and poly 3-((3-(2-(3-acetylbenzoyl)hydrazine carbonyl)-5-(2- methylhydrazinecarbonyl)phenyl) carbamoyl)phenyl acetate 32}

The bis-hydrazide 28 ( $1 \mathrm{~g}, 2.7 \mathrm{mmol}$ ) and isophthaloyl chloride 30 [19-22] (0.5 g, 2.4 mmol) in DMA (10 ml) was stirred at rt for $3 \mathrm{~h}$ and then poured on to cooled water. The polymer was collected filtration, washed with water, ethyl alcohol, water again and dried in a vacuum oven at $60^{\circ} \mathrm{C}$ for $24 \mathrm{~h}$. The polyamide 31 was obtained in $94 \%$ yield $(1.2 \mathrm{~g})$; m.p. $>300^{\circ} \mathrm{C}, \eta_{\mathrm{inh}}=0.362 \mathrm{dL} / \mathrm{g}$. Elemental analysis calculated for $31\left(\mathrm{C}_{25} \mathrm{H}_{21} \mathrm{~N}_{5} \mathrm{O}_{8}\right)_{\mathrm{n}}$ : C, 57.80; $\mathrm{H}$,
4.00; N, 13.48; Found: C,57.51 ; H, 4.28; N, 13.83. IR $\left(\mathrm{v} \mathrm{cm}^{-1}\right): 3310,2827,2693,2622,2518,2354,2326,1654$, $1593,1553,1512,1428,1356,1307,1254,1181,1117$, 1007, 955, 891, 841, 737, 687, 637, 594.

Polyamide 32 was prepared in a similar method starting by 5-(3-acetoxybenzoylamino) isophthalohydrazide $\mathbf{2 9}$ and isophthaloyl chloride 30 in a $94 \%\left(1.2\right.$ g); m.p. $>300^{\circ} \mathrm{C}$. Elemental analysis calculated for $32\left(\mathrm{C}_{25} \mathrm{H}_{21} \mathrm{~N}_{5} \mathrm{O}_{8}\right)_{\mathrm{n}}$ : $\mathrm{C}$, 57.80; H, 4.00; N, 13.48; Found: C, 58.21; H, 3.69; N, 13.09. IR $\left(\mathrm{u} \mathrm{cm}^{-1}\right): 3268,2951,2350,2299,1721,1655$, 1599, 1549, 1440, 1343, 1294, 1250, 1122, 998, 951, 901, $881,838,801,754,683,600,532$.

Synthesis of 4-((3-(5-(3-acetylphenyl)-1,3,4-oxadiazol-2-yl)-5(5-methyl-1,3,4-oxadiazol-2-yl)phenyl)carbamoyl)phenyl acetate 33 and 3-((3-(5-(3-acetyl phenyl)-1,3,4-oxadiazol-2yl)-5-(5-methyl-1,3,4-oxadiazol-2-yl)phenyl)- carbamoyl) phenyl acetate 34

The polyhydrazide 31 (0.5 g, $0.96 \mathrm{mmol})$ was mixed with thionyl chloride $(10 \mathrm{ml})$ and the mixture was refluxed for $6 \mathrm{~h}$. The excess of thionyl chloride and volatiles were distilled off by and the resulted solid was treated with hexane and dried under vacuum to furnish the polymer 33; m.p. $>300^{\circ} \mathrm{C}, \eta_{\mathrm{inh}}=0.341 \mathrm{dL} / \mathrm{g}$. IR $\left(\mathrm{u} \mathrm{cm}^{-1}\right): 4388$, 4300, 4081, 3896, 3849, 3794, 3729, 3707, 3664, 3216, 3080, 2923, 2355, 2328, 1822, 1704, 1652, 1602, 1548, $1511,1445,1332,1205,959,902,845,753,668$. Elemental analysis calculated for $\left(\mathrm{C}_{26} \mathrm{H}_{17} \mathrm{~N}_{5} \mathrm{O}_{7}\right)_{\mathrm{n}}: \mathrm{C}, 61.05 ; \mathrm{H}, 3.32$; N, 13.69; Found: C, 59.83 ; H, 3.77; N, 13.42. 
Table 1 Optical properities of polyamides 12-25, polyhydrazides 31,32 and poly(1,3,4-oxadiazoles) 33,34

\begin{tabular}{lccc}
\hline Polymer No & ${ }^{\mathbf{a}} \lambda_{\text {abs }}(\mathbf{n m})$ & $\boldsymbol{\varepsilon}^{\mathbf{b}}\left(\mathbf{M}^{-\mathbf{1}} \mathbf{c m}^{-\mathbf{1}}\right)$ & ${ }^{\mathbf{c}} \lambda_{\mathbf{e m}}(\mathbf{n m})\left({ }^{\mathbf{d}} \lambda_{\mathbf{e x}}\right.$ at $\left.\mathbf{3 0 0} \mathbf{~ n m}\right)$ \\
\hline $\mathbf{1 2}$ & 292 & 2400 & 345,647 \\
$\mathbf{1 3}$ & 288 & 4300 & 361,696 \\
$\mathbf{1 4}$ & 286 & 20000 & 343,642 \\
$\mathbf{1 5}$ & 278 & 7100 & 341,650 \\
$\mathbf{1 6}$ & 284 & 12000 & 345,650 \\
$\mathbf{1 7}$ & 276 & 4600 & 338,646 \\
$\mathbf{1 8}$ & 297 & 17200 & 364,407 \\
& 325 & 18100 & 420,744 \\
$\mathbf{1 9}$ & 285 & 6900 & 362,644 \\
$\mathbf{2 0}$ & 323 & 9000 & \\
$\mathbf{2 1}$ & 295 & 23500 & 347,642 \\
$\mathbf{2 3}$ & 291 & 8500 & 340,652 \\
$\mathbf{2 4}$ & 282 & 8700 & 341,646 \\
$\mathbf{2 5}$ & 309 & 25000 & 346,658 \\
$\mathbf{3 1}$ & 286 & 5200 & 336,376 \\
$\mathbf{3 2}$ & 305 & 5700 & 400,684 \\
$\mathbf{3 4}$ & 280 & 7700 & 357,502 \\
& 274 & 8400 & $363(\mathrm{~W}), 427$ \\
$\mathbf{3 4}$ & 283 & 10000 & $360(\mathrm{~W}), 431$ \\
& 277 & 6800 & $363(\mathrm{w}), 428,529(\mathrm{w})$, \\
& & &
\end{tabular}

${ }^{\mathrm{a}} \lambda_{\mathrm{abs}}$ : maximum wavelengths of absorption.

${ }^{b} \varepsilon$ : the molar absorption coefficient calculated from Beer-Lambert equation

( $A=\varepsilon \times c \times l)$; where $A$ is absorbance, $c$ is concentration, $I=1 \mathrm{~cm}$ ).

${ }^{\mathrm{C}} \lambda_{\mathrm{em}}$ : maximum wavelengths of emission.

${ }^{\mathrm{d}} \lambda_{\mathrm{ex}}$ : maximum wavelengths of excitation.

In a similar procedure, the polymer $\mathbf{3 4}$ was prepared from the polyhydrazide 32 and the following data were recorded: Yield: $87 \%\left(0.43\right.$ g); m.p. $>300^{\circ} \mathrm{C}, \eta_{\text {inh }}=0.331$ dL/g. IR $\left(\mathrm{v} \mathrm{cm}^{-1}\right)$ : 3436, 2925, 1717, 1657, 1594, 1554, 1445, 1342, 1295, 1256, 1127, 1001, 903, 839, 755, 680, 605. Elemental analysis calculated for $\mathbf{3 4}\left(\mathrm{C}_{26} \mathrm{H}_{17} \mathrm{~N}_{5} \mathrm{O}_{7}\right)_{\mathrm{n}}$ : C, 61.05; H, 3.32; N, 13.69; Found: C,62.44; H, 3.74; N, 13.31 .

\section{Polymer Particles Synthesis (General Method)}

The diacid chloride 10 or $\mathbf{1 1}(0.5 \mathrm{mmol})$ and the appropriate diamine $(0.5 \mathrm{mmol})$ were each dissolved in dioxane $(50 \mathrm{~mL})$. Distilled water $(15 \mathrm{~mL})$ was added to the solution of the diamine followed by the addition of the entire acid chloride solution at once. The resulted turbid solution was ultrasonicated at $42 \mathrm{KHz}$ in a water bath for a period of $30 \mathrm{~min}$. The polymer colloidal solution was extracted by centrifugal separation for $15 \mathrm{~min}$. at 15,000 rpm and the resulted precipitate were carefully washed with methanol and water to purify the product of any unreacted monomer. The polymer samples were then dried at $60^{\circ} \mathrm{C}$ for $10 \mathrm{~h}$ then kept in a vacuum desiccator.

\section{Results and discussions}

Synthesis of polyamides containing pendent $m$ - and p-acetoxybezamides groups

The production of new types of aromatic polyamides containing pendant structures comprised of $m$ - and $p$ acetoxybenzamide groups, where the acetoxybenzamide groups act as signaling units due to their fluorescent and chromogenic characteristics, and studying of their properties is the major objective of our study. One of the most important tasks in this study is to analyze and predict their properties such as solubility, optical and fluorescence emission properties and thermal stability with respect to their chemical structure. 5-(4-Acetoxybenzamido)isophthaloyl chloride $\mathbf{1 0}$ [11] was synthesized by a sequence of reactions in which $p$-hydroxybenzoic acid 1 reacted with acetic anhydride to give $p$-acetoxybenzoic acid 3 that by further treatment with thionyl chloride gave the corresponding acid chloride; the latter reacted with 5 -aminoisophthalic acid 7 to produce $p$-(acetoxybenzamido)isophthalic acid $\mathbf{8}$ which, by further treatment with thionyl chloride, gave $p$-(acetoxybenzamido)isophthaloyl chloride 10, Scheme 1. Following similar sequence of reactions, 5-(3-acetoxybenzamido)isophthaloyl chloride $\mathbf{1 1}$ was prepared starting from $m$-hydroxybenzoic acid 2 . Polyamides 12-25 (Figure 1) were synthesized in moderate yields by direct solution polycondensation of an equimolar mixture of the acids chlorides 10-11 with $p$-phenylenediamine, $m$-phenylenediamine, 2,6-diaminopyridine, 4,4'-diaminodiphenylsulfone, 4,4'-diaminodiphenyl ether, 4,4'-diaminodiphenylmethane and benzidine in $\mathrm{N}, \mathrm{N}$-dimethylacetamide solution. The polymer structures were confirmed by elemental analysis, IR and UV-vis spectroscopy. Elemental analyses are in a good agreement with the proposed structures. A detailed description of the physical properties of the polymers 12-25 are given in the experimental section.

Our attention focused next on the synthesis of new types of aramide nanoparticles containing bulky pendent groups. Polymeric aromatic nanoparticles can be prepared by either emulsion or interfacial polymerizations. Additionally, a popular method used for polymeric nanoparticles preparation is solvent displacement, also referred to as nanoprecipitation [24]. The basic principle of this technique is based on the interfacial deposition of a polymer after displacement of a semipolar solvent, miscible with water, from a lipophilic solution. Rapid diffusion of the solvent into the non-solvent phase results in a decrease of interfacial tension between the two phases, which increases the surface area and leads to the formation of small droplets of organic solvent. The key variables determining the success of the method and affecting the physicochemical properties of nanoparticles are those associated with the conditions of adding the organic phase to the aqueous phase, such as organic phase injection rate, 

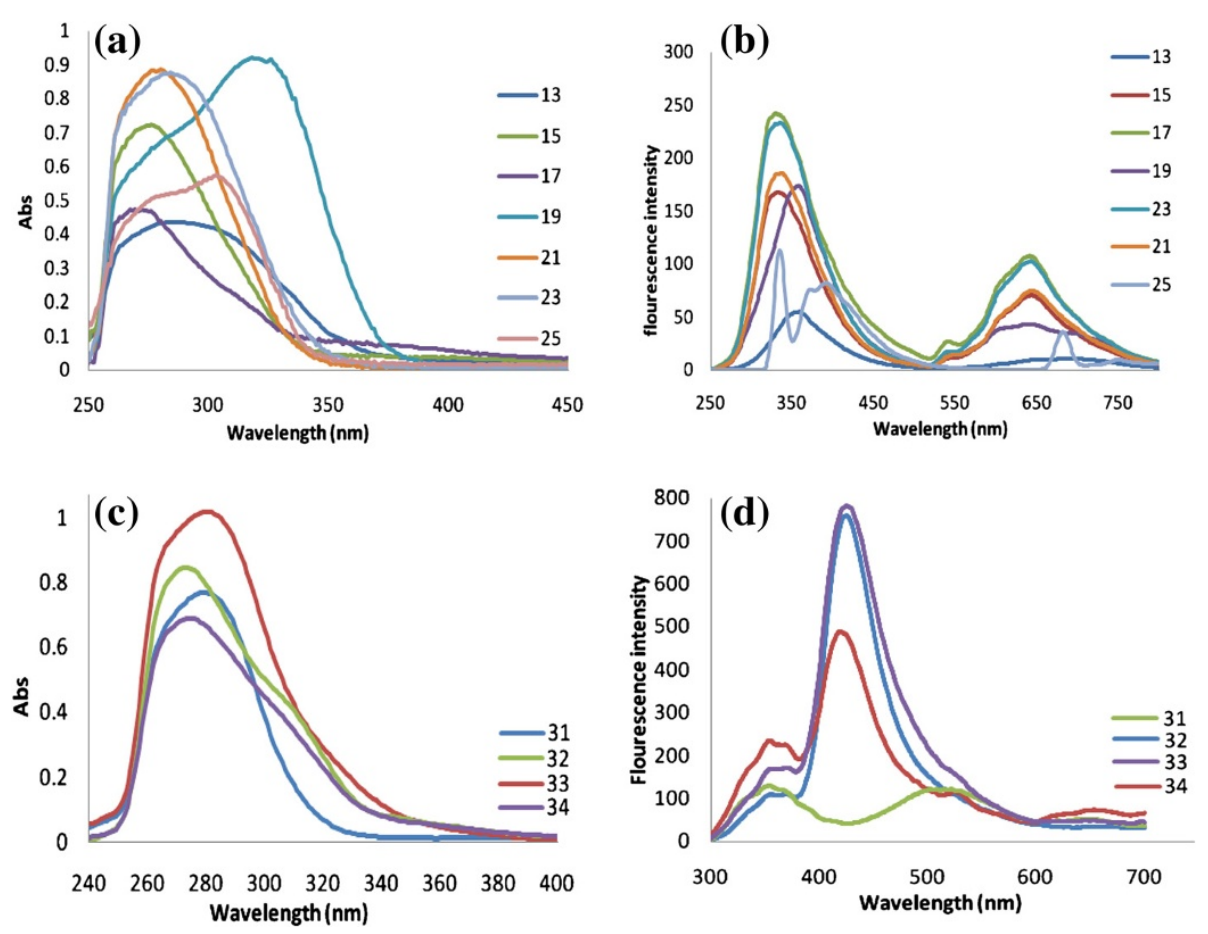

Figure 3 UV-vis absorption images and fluorescent spectra of the polyamides 13, 15, 17, 19, 21, 23, 25.

aqueous phase agitation rate, the method of organic phase addition and the organic phase to aqueous phase ratio. Likewise, nanoparticle characteristics are influenced by the nature and concentration of their components [25,26]. The process of particle formation in the nanoprecipitation method comprises three stages: nucleation, growth and aggregation. The rate of each step determines the particle size and the driving force of these phenomena is the ratio of polymer concentration over the solubility of the polymer in the solvent mixture. The separation between the nucleation and the growth stages is the key factor for uniform particle formation [27]. As a representative example, the nanoparticles series 12, 14, 16, 18, 20 and 24 were prepared by ultrasonication of $0.5 \mathrm{mmol}$ of $p$-phenylenediamine, $m$-phenylenediamine, 2,6-diaminopyridine, benzidine, diaminodiphenylether and diaminodiphenylsulfone, respectively, with $0.5 \mathrm{mmol}$ of the acid chloride $\mathbf{1 0}$ in a total of $115 \mathrm{~mL}$ dioxane solution containing distilled water $(15 \mathrm{~mL})$ (i.e., $50 / 15 \mathrm{~mL}$ dioxane-water $v / v$ diamine solution and $50 \mathrm{~mL}$ dioxane acid chloride solution) followed by centrifugal separation at 15,000 rpm for $30 \mathrm{~min}$. Mixing 1,4-dioxane with $\mathrm{H}_{2} \mathrm{O}$ was essential for many reasons, such as controlling the particle morphology, playing an important role in determining the polarity of the reaction solution and as a reaction accelerator [20-23]. As judged by SEM photographs, (Figure 2), the prepared polyamides were obtained as well-separated spherical nanoparticles while aggregated particles of the aramide containing pyridine 16 were obtained. The average diameters (standard deviation) were 12; $67.5 \mathrm{~nm}(2.54), 14 ; 55.86$ (5.35), 16; $39.65 \mathrm{~nm}$ (3.69), 18; $135.14 \mathrm{~nm}$ (11.83), 20; $130.50 \mathrm{~nm}$ (15.82) and 24; $115.92 \mathrm{~nm}$ (10.37), respectively. The formation of such aggregate may be attributed to the molecular self assembly via $\mathrm{H}$-bond directed organization of molecular precursors [28]. Amides embody self-complementary recognition groups defined by homomeric H-bond donoracceptor pairs [29]. Noteworthy, addition of particular amount of water $(15 \% \mathrm{v} / \mathrm{v})$ to this reaction system is essential, not only for the formation of spherical particles, but also to diminish the aggregation of these particles. The tendency of spherical particles formation of such aramides may be correlated to the dispersion stability of particles in the reaction solution or the precipitation mechanism of the particles. The formation mechanism of polymers is related to the effect of water on the micelle structure. Micelles grow in the presence of water to spherical micelles [20-23].

5-(4-acetoxybenzoylamino)isophthalate $\mathbf{2 6}$ and methyl 5-(3-acetoxybenzoylamino)isophthalate 27 were prepared in quantitative yield from the corresponding acids $\mathbf{8}$ and $\mathbf{9}$, respectively, Scheme 2. Boiling of the esters $\mathbf{2 6}$ and 27 with hydrazinehydrate furnished the expected 5-(4-acetoxybenzoylamino)isophthalohydrazide 28 and 5(3-acetoxybenzoylamino)isophthalohydrazide 29 , respectively. The hydrazide polymers $\mathbf{3 1}$ and $\mathbf{3 2}$ were efficiently prepared in quantitative yields by solution polycondensation of the bis-hydrazides $\mathbf{2 8}$ and $\mathbf{2 9}$, respectively, with the 
Table 2 Thermoanalytical data of the prepared polymers 12-25

\begin{tabular}{|c|c|c|c|c|c|c|c|c|c|}
\hline No & DTG $\left({ }^{\circ} \mathrm{C}\right)$ & Wt.loss (\%) & Residue (\%) & $\mathrm{LOI}^{\mathrm{a}}$ & No & DTG $\left({ }^{\circ} \mathrm{C}\right)$ & Wt.loss (\%) & Residue (\%) & $\mathrm{LOI}^{\mathrm{a}}$ \\
\hline \multirow[t]{4}{*}{12} & 268 & 16.7 & 6.90 & 19.7 & 18 & 265 & 18.3 & 11.93 & 21.7 \\
\hline & 425 & 22.0 & & & & 350 & 15.5 & & \\
\hline & 561 & 54.4 & & & & 461 & 8.8 & & \\
\hline & & & & & & 560 & 45.4 & & \\
\hline \multirow[t]{2}{*}{13} & 279 & 14.2 & 3.70 & 18.4 & 19 & 291 & 10.1 & 6.98 & 19.7 \\
\hline & 553 & 82.1 & & & & 578 & 82.8 & & \\
\hline \multirow[t]{4}{*}{14} & 286 & 9.3 & 17.17 & 23.8 & 20 & 332 & 9.0 & 3.97 & 18.5 \\
\hline & 552 & 73.5 & & & & 370 & 18.4 & & \\
\hline & & & & & & 506 & 15.7 & & \\
\hline & & & & & & 614 & 38.9 & & \\
\hline \multirow[t]{2}{*}{15} & 294 & 12.5 & 6.30 & 19.5 & 21 & 367 & 13.2 & 8.10 & 20.2 \\
\hline & 540 & 81.2 & & & & 605 & 78.6 & & \\
\hline \multirow[t]{3}{*}{16} & 206 & 10.4 & 3.62 & 18.4 & 23 & 274 & 9.7 & 3.83 & 18.5 \\
\hline & 296 & 17.6 & & & & 539 & 86.4 & & \\
\hline & 590 & 68.3 & & & & & & & \\
\hline \multirow[t]{3}{*}{17} & 275 & 29.6 & 5.32 & 19.1 & 24 & 389 & 15.9 & 6.04 & 19.4 \\
\hline & 348 & 32.1 & & & & 584 & 77.9 & & \\
\hline & 524 & 32.9 & & & & & & & \\
\hline
\end{tabular}

alimiting oxygen index.

readily available isopthaloyl chloride 30 [19-22] in $N, N$ dimethylacetamide. The hydrazide polymers $\mathbf{3 1}$ and $\mathbf{3 2}$ were cyclodehydrated through heating with thionyl chloride for several hours to furnish the corresponding poly (1,3,4-oxadiazole-amide)s 33 and 34, respectively. Probably due to the increased length of conjugated chain and/ or the formation of charge-transfer complex between the oxadiazole ring and the aromatic unit, the hydrazide polymers 33 and 34 turned into darkened and deep brown after cyclodehydration. Conversion of the hydrazide group to the 1,3,4-oxadiazole ring could be monitored by FT-IR.

Table 3 Thermoanalytical data of the polyhydrazides $\mathbf{3 1}$, 32 and poly (1,3,4-oxadiazole-amide)s 33, 34

\begin{tabular}{lcccc}
\hline No & DTG $\left({ }^{\circ} \mathbf{C}\right)$ & Wt.loss (\%) & Residue (\%) & LOI $^{\mathbf{a}}$ \\
\hline $\mathbf{3 1}$ & 308 & 19.0 & 7.61 & 20.0 \\
& 549 & 73.3 & & \\
$\mathbf{3 2}$ & 334 & 37.5 & 1.68 & 17.6 \\
& 405 & 20.0 & & \\
& 574 & 40.7 & & \\
$\mathbf{3 3}$ & 232 & 18.5 & 6.23 & 19.4 \\
& 443 & 24.8 & & \\
& 570 & 50.3 & & \\
$\mathbf{3 4}$ & 258 & 34.8 & 2.64 & \\
& 318 & 31.3 & & \\
& 551 & 31.3 & & \\
\end{tabular}

alimiting oxygen index.
Conversion of the acyl hydrazide group to the 1,3,4-oxadiazole unit can be confirmed by the disappearance of the $\mathrm{N}-\mathrm{H}$ stretching absorption at $3252 \mathrm{~cm}^{-1}$ and the carbonyl peak at $1653 \mathrm{~cm}^{-1}$, together with the appearance of the oxadiazole characteristic bands at $1550-1570 \mathrm{~cm}^{-1}, 1070$ $\mathrm{cm}^{-1}$ and 980-990 $\mathrm{cm}^{-1}$, [30] with a broadening and minor shift of the bands in the polymer spectra. Other characteristic vibrations include the aromatic skeletal stretching at 1610 and $1480 \mathrm{~cm}^{-1}$. TGA, as discussed subsequently, was also used to investigate cyclization to the oxadiazole structure.

\section{Physical properties of the prepared polymers Solubility}

All of the polyamides 12-25 and polyhydrazides 31-32 were readily soluble in polar solvents such as NMP, DMAc, DMF and DMSO while insoluble in boiling alcoholic or halogenated solvents. The observed good solubility compared with that of related aromatic polyamides and aromatic polyoxadiazole-amides are due to the presence of voluminous acetoxybenzamide side groups which prevent the packing of the macromolecules through hydrogen bonds between amide groups in the chain. Due to the increased chain rigidity, the poly(amide-1,3,4-oxadiazole)s 33-34 showed a dramatically decreased solubility as compared to the corresponding hydrazide prepolymers. The oxadiazole based polymers were insoluble in all the organic solvents tested. This also indicates that these oxadiazole polymers exhibit good chemical stability. 


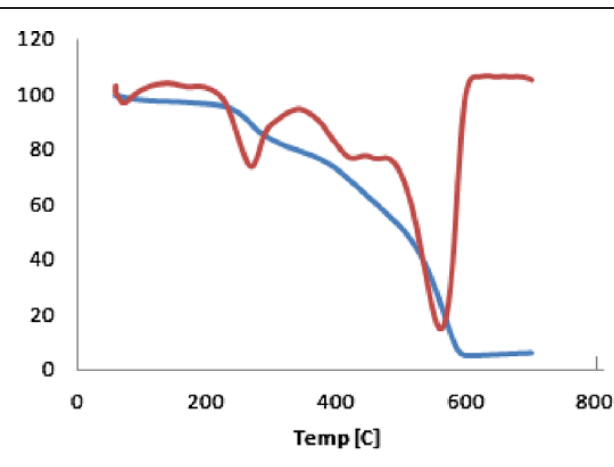

12

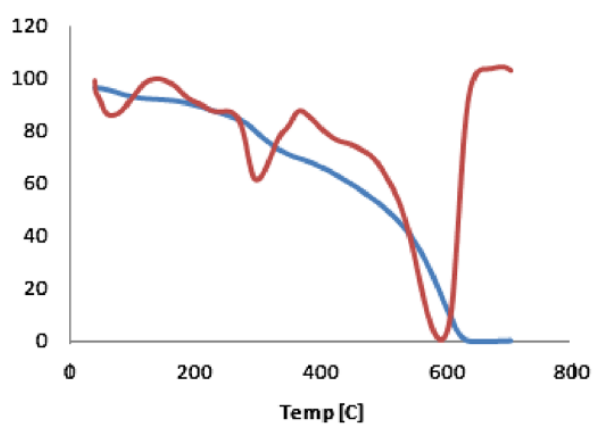

16

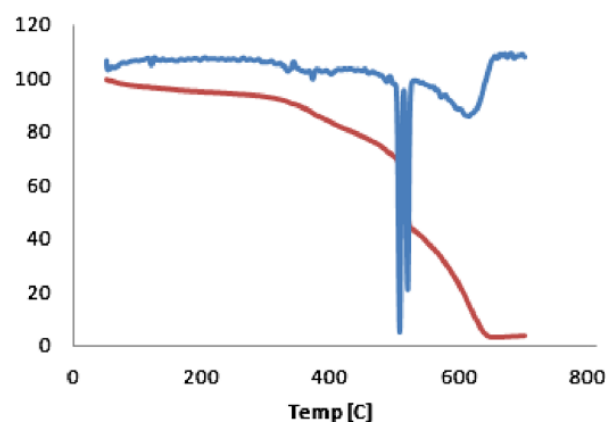

20

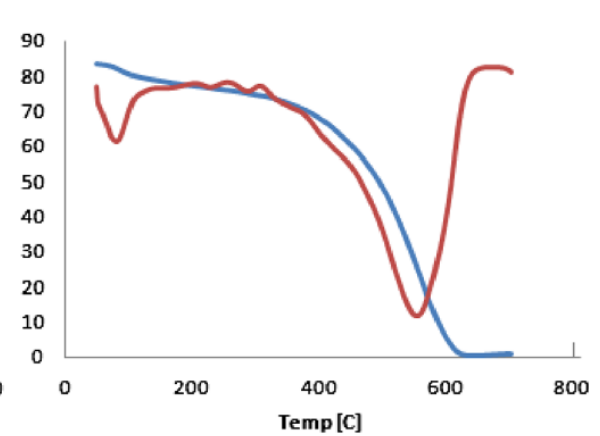

14

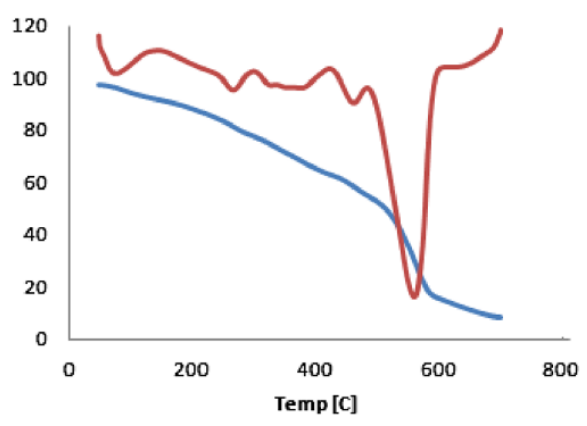

18

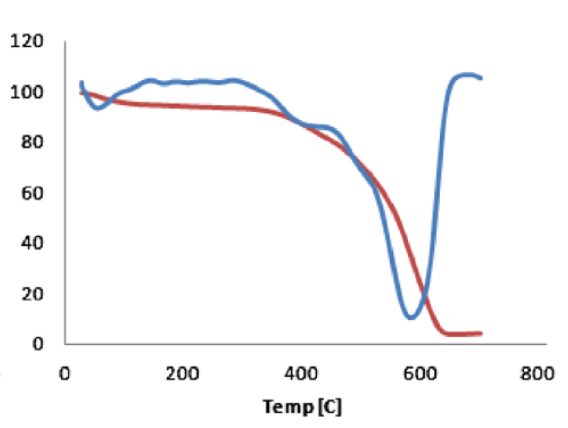

24

Figure 4 TG/DTG curves of the polymeric nanoparticles 12, 14, 16, 18, 20, 24.

\section{Inherent viscosity}

The inherent viscosity $\left(\eta_{\text {inh }}\right)$ of the polymers, as a suitable criterion for evaluation of molecular weight, was measured at a concentration of $0.5 \mathrm{~g} / \mathrm{dL}$ in DMSO at $30^{\circ} \mathrm{C}$. It was in the range of $0.359-0.765 \mathrm{dL} / \mathrm{g}$ that showed moderate molecular weights. From the data it is concluded that the prepared linear symmetric metapolymers exhibited high $\eta_{\text {inh }}$ values and thus high degree of polymerization.

\section{FTIR spectroscopy}

The FT-IR spectra of the prepared polymers exhibited characteristic absorbance at $\mathrm{u} 3300$ and $\mathrm{v} 1650 \mathrm{~cm}^{-1}$ corresponding to the $\mathrm{N}-\mathrm{H}$ and $\mathrm{C}=\mathrm{O}$ stretching of amide group, respectively. Bands at 03050 and $01600 \mathrm{~cm}^{-1}$ were assigned to the aromatic $\mathrm{H}-\mathrm{C}_{\mathrm{str}}$ and $\mathrm{C}-\mathrm{C}_{\mathrm{str}}$, respectively. The absorption bands appearing at $1020 \mathrm{~cm}^{-1}$ and 960 $\mathrm{cm}^{-1}$ were characteristic of $=\mathrm{C}-\mathrm{O}-\mathrm{C}=$ stretching in 1,3,4-oxadiazole rings. A detailed description of the IR data of the polyamides $\mathbf{1 2 - 2 5}$ and 31-34 are given in the experimental section.

\section{UV-vis and fluorescence emission studies}

The optical properties of polymeric particles 12-25 and 31-34 were investigated by UV-vis spectroscopy in DMSO using a polymer concentration of $\sim 2 \mathrm{mg} / 10 \mathrm{~mL}$. Comparison between the polyamide particles clearly revealed that the absorbance characteristics of the polymer 


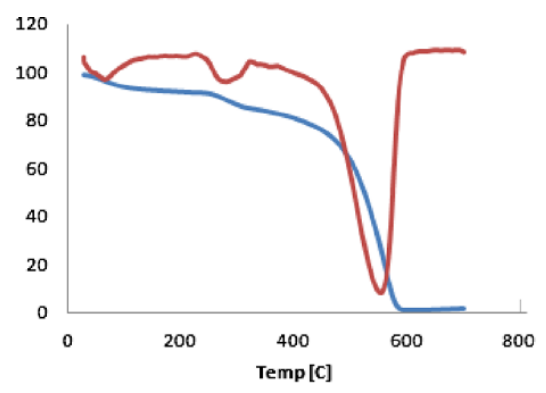

13

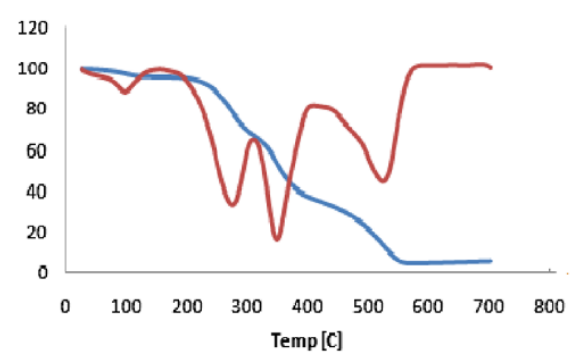

19

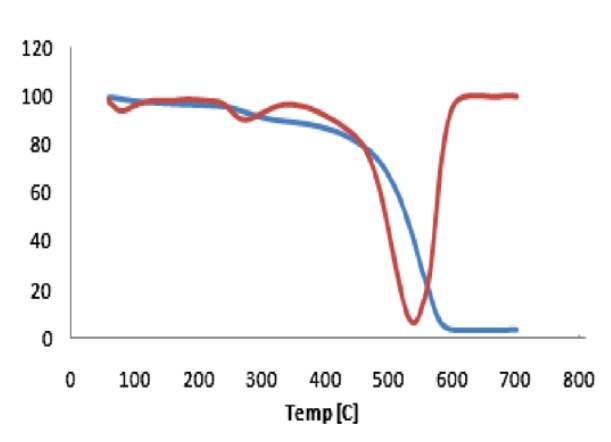

23

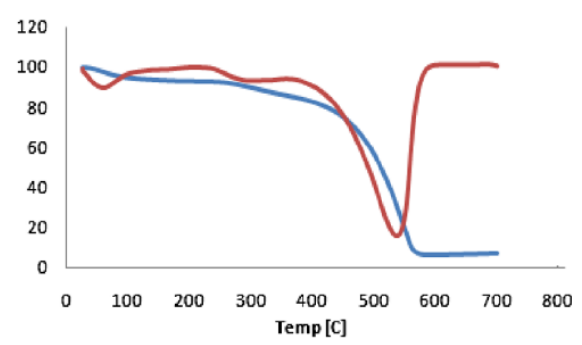

15

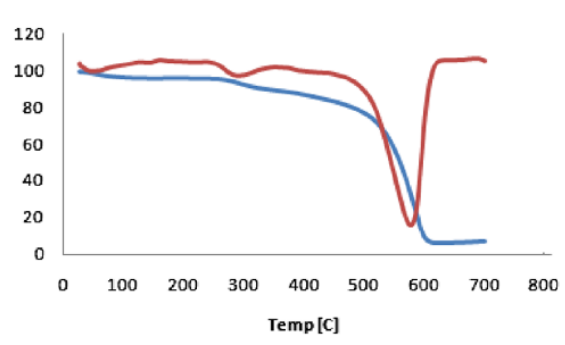

21

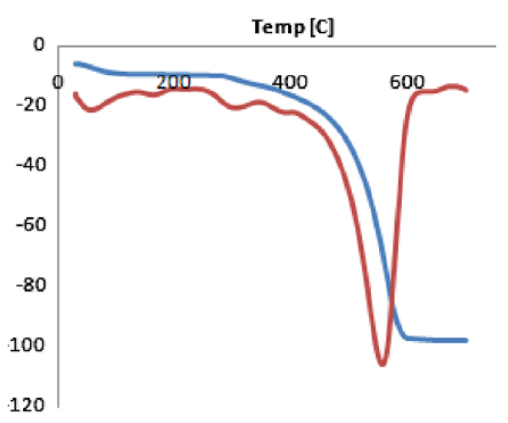

25

Figure 5 TG/DTG curves of the polymeric nanoparticles 13, 15, 19, 21, 23, 25.

are affected by the linear conjugated system. Spectralluminescent characteristics of the prepared polymers 1225 and 31-34 in DMSO are presented in Table 1. The studied polymers have wide absorption spectral bands with maxima situated between 276 and $325 \mathrm{~nm}$, principally due to electronic transitions of electrons in long conjugated sequence of $\pi$-bonds ( $\pi \rightarrow \pi^{*}$ transitions) and electronic $n \rightarrow \pi^{*}$ transitions of non-bonding lone-pair electrons on heteroatoms in $\pi$-bonds. The values of molar extinction coefficients are in the range from $2400 \mathrm{M}^{-1} \mathrm{~cm}^{-1}$ to $25000 \mathrm{M}^{-1} \mathrm{~cm}^{-1}$. For the polyamides containing $m$-acetoxybenzamide pendant groups the positions of absorption spectra maxima are shifted, as compared to those containing $p$-acetoxybenzamide pendant groups, to the shortwavelength region up to $10 \mathrm{~nm}$. Interestingly, polymers 18 and 19 derived from benzidine exhibited additional long shoulders at $\lambda 325 \mathrm{~nm}$ and $\lambda 323 \mathrm{~nm}$, respectively. The presence of additional bands in 18 and 19 absorption spectra could be due to the longer conjugation sequence of $\pi$-bonds compared to other polymers.

The PL spectra were recorded at $300 \mathrm{~nm}$ excitation wavelength using a polymer concentration of $\left(10^{-5}\right)$ (2 mg / $10 \mathrm{ml}$ (DMSO) diluted up to $100 \mathrm{ml}$ ). The excitation maxima positions of the studied polyamides containing $m$-acetoxybenzamide groups are shifted to the lower-wavelength spectral region relatively to those containing $p$-acetoxybenzamide pendant groups. In general, most polyamides exhibited two excitation maxima; longwavelength bands situated in the range 696-642 $\mathrm{nm}$ and lower-wavelength bands in the range 362-338 $\mathrm{nm}$. In the case of polyamides 18 and 25 four excitation maxima were observed. Polymer 18 exhibited the main bands with maximum at $744 \mathrm{~nm}, 420 \mathrm{~nm}, 407 \mathrm{~nm}$ and $336 \mathrm{~nm}$ while polyamide 25 showed bands at $686 \mathrm{~nm}$, $400 \mathrm{~nm}, 376 \mathrm{~nm}$ and $336 \mathrm{~nm}$. Figure 3 shows the UV-vis absorption images and fluorescent spectra of selected 


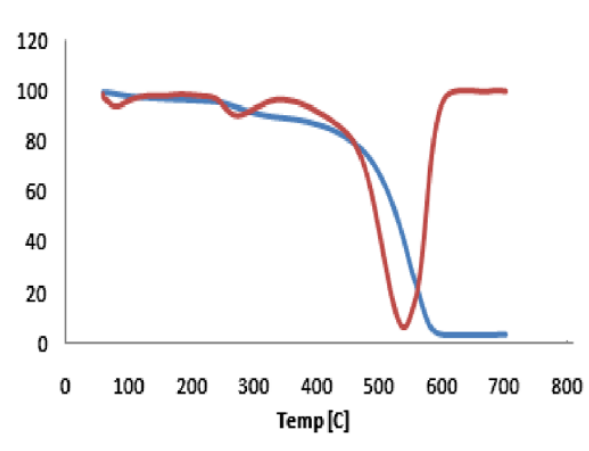

31

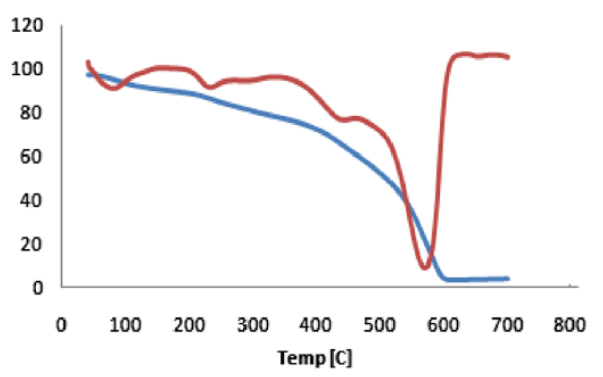

33

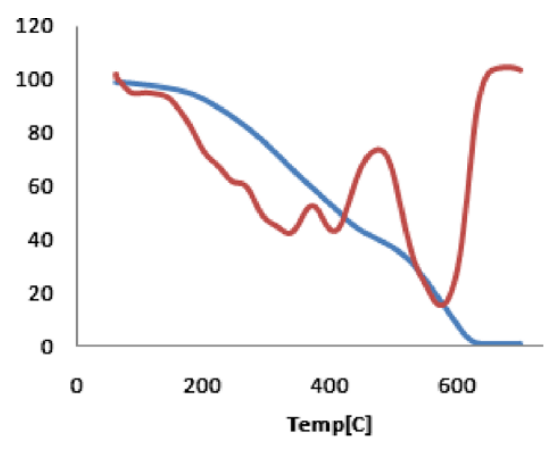

32

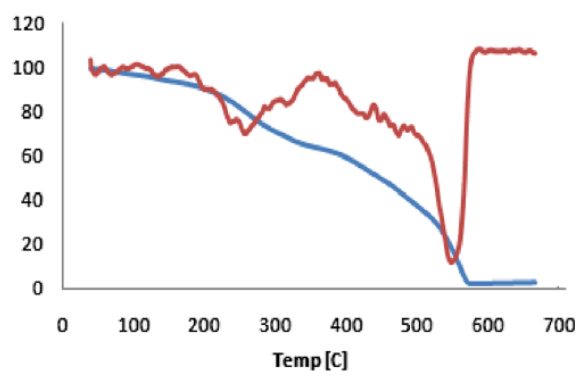

34

Figure 6 TG/DTG curves of the polyhydrazides 31, 32 and poly(1,3,4-oxadiazole-amide)s 33, 34.

polyamide series, polyhydrazides 31,32 and poly $(1,3,4-$ oxadiazole-amide)s 33, 34.

Polyhydrazides 31 and 32 exhibited major absorption bands at $280 \mathrm{~nm}$ and $274 \mathrm{~nm}$, respectively, mainly due to $\pi$-bonds ( $\pi \rightarrow \pi^{*}$ transitions) of the aromatic units. In addition, 31 and 32 exhibited two major excitation maxima (recorded at $300 \mathrm{~nm}$ ) at $502 \mathrm{~nm}$ and $427 \mathrm{~nm}$ and low intensity shoulders at $357 \mathrm{~nm}$ and $363 \mathrm{~nm}$, respectively. Poly(1,3,4-oxadiazole-amide)s $\mathbf{3 3}$ and $\mathbf{3 4}$ showed two strong UV absorption peaks at $283 \mathrm{~nm}$ and $277 \mathrm{~nm}$, respectively. The PL spectra of $\mathbf{3 3}$ and $\mathbf{3 4}$ showed two strong excitation peaks at $431 \mathrm{~nm}$ and $428 \mathrm{~nm}$, in addition, to two little excitation bands at $360 \mathrm{~nm}$ and $363 \mathrm{~nm}$, respectively. A weak excitation band at $529 \mathrm{~nm}$ and a little shoulder at $637 \mathrm{~nm}$ were also observed for the oxadiazole 34 .

From the electronic and spectral points of view, the oxadiazole ring is similar to a para-phenylene structure and has a strong electron-withdrawing character. Due to the similarity with para-phenylene unit, known as highly thermoresistent, the 1,3,4-oxadiazole ring is called pseudophenylene [31]. However, the introduction of 1,3,4-oxadiazole rings in the macromolecular chains motivated by many other features such as: (a) 1,3,4-oxadiazole ring is free of hydrogen and, therefore, poly(1,3,4-oxadiazole)s maintain their properties during heating, in air, better than other polymers; (b) conjugation between 1,3,4-oxadiazole and other aromatic rings in polymers is similar to that of polyphenylenes; (c) 1,3,4-oxadiazole ring is free of tension; (d) 1,3,4-oxadiazole cycle doesn't have any possibilities of rearrangement; (e) 1,3,4-oxadiazole ring has a structural symmetry and it is thermally unreactive. From the data given in Table 1 , we noticed that the absorption maxima of polymers 12, 13 ( $p$-phenylene-containing polymers) are comparable with that of oxadiazole-containing polymers 33, 34. Polymers-containing oxadiazoles units 33, 34 present strong excitation peaks around 431 and $428 \mathrm{~nm}$, in addition, two lower excitation bands at $360,363 \mathrm{~nm}$, respectively, while the major excitation bands in case of $\mathbf{1 2}$, 13 were found at lower wavelengths at $345,361 \mathrm{~nm}$, respectively, in addition, two low intensity excitation peaks at 647, $696 \mathrm{~nm}$, respectively. Solely, polymer 34 exhibit additional peaks at higher wavelengths at $529 \mathrm{~nm}$ (weak band) and $637 \mathrm{~nm}$ (weak shoulder) may be due to other chromophores present in the macromolecular chain.

Structure-PL property relationship may achieved further trends and conclusions:

\section{Polyamides 14 and 16 , containing} $p$-acetoxybenzamide pendant groups, derived from $m$-phenylenediamine and 2,6-diaminopyridine, respectively, exhibited almost similar strong emission peaks at about $343 \mathrm{~nm}$ and $345 \mathrm{~nm}$. However, their analogues 15,17 containing $m$-acetoxybenzamide 
Table 4 Kinetic parameters of the polyamides $12-25$

\begin{tabular}{|c|c|c|c|c|c|c|c|c|c|c|c|c|}
\hline No & Slope DTA & $\Delta \mathrm{E}^{\mathrm{a}}$ & $a$ & b & $\mathrm{S}^{\mathbf{b}}$ & $\mathrm{N}^{\mathrm{c}}$ & $a_{m}^{d}$ & $\mathrm{~T}_{\mathrm{m}}(\mathrm{K})$ & $\mathrm{Z}^{\mathrm{e}}$ & $\Delta S^{f}$ & $\Delta \mathrm{H}^{\mathrm{g}}$ & ${ }^{h^{h}} R^{2}$ \\
\hline \multirow[t]{2}{*}{12} & -23.5 & 195.5 & 1.3 & 0.7 & 5.3 & 1.7 & 0.5 & 537.7 & 3.9 & -0.23 & -128.1 & 0.96 \\
\hline & -11.1 & 93.0 & 2.9 & 1.5 & 5.2 & 1.7 & 0.5 & 833.5 & 1.1 & -0.25 & -210.3 & 0.97 \\
\hline 13 & -12.7 & 105.6 & 3.6 & 1.2 & 8.5 & 2.1 & 0.4 & 823.4 & 0.7 & -0.25 & -210.2 & 0.95 \\
\hline \multirow[t]{2}{*}{14} & -10.5 & 87.7 & 1 & 0.7 & 4.0 & 1.5 & 0.5 & 815.7 & 1.0 & -0.25 & -205.9 & 0.99 \\
\hline & -9.4 & 78.5 & 6 & 3 & 5.7 & 1.7 & 0.5 & 821.2 & 0.9 & -0.25 & -208.2 & 0.96 \\
\hline 15 & -17.4 & 145.0 & 4 & 1.9 & 6.0 & 1.8 & 0.5 & 810.1 & 1.8 & -0.24 & -201.0 & 0.99 \\
\hline \multirow[t]{2}{*}{16} & -29.4 & 244.7 & 0.6 & 0.5 & 3.4 & 1.3 & 0.5 & 648.4 & 4.0 & -0.23 & -155.4 & 0.96 \\
\hline & -17.0 & 141.9 & 4.8 & 1.6 & 8.5 & 2.1 & 0.4 & 867.7 & 1.6 & -0.24 & -216.5 & 0.98 \\
\hline \multirow[t]{4}{*}{17} & -10.2 & 85.1 & 0.9 & 0.6 & 4.2 & 1.5 & 0.5 & 405.1 & 1.3 & -0.24 & -99.2 & 0.98 \\
\hline & -23.6 & 196.9 & 0.6 & 0.7 & 2.4 & 1.1 & 0.6 & 554.2 & 2.3 & -0.24 & -134.7 & 0.97 \\
\hline & -11.8 & 98.8 & 0.4 & 1 & 1.1 & 0.7 & 0.6 & 629.3 & 0.9 & -0.25 & -158.1 & 0.98 \\
\hline & -53.9 & 448.6 & 3 & 1.5 & 5.7 & 1.7 & 0.5 & 801.9 & 3.6 & -0.24 & -194.3 & 0.99 \\
\hline \multirow[t]{3}{*}{18} & -20.7 & 172.3 & 0.4 & 1.2 & 0.9 & 0.7 & 0.6 & 365.8 & 5.5 & -0.23 & -85.0 & 0.86 \\
\hline & -36.3 & 302.4 & 1.3 & 0.7 & 5.3 & 1.7 & 0.5 & 736.5 & 4.4 & -0.24 & -176.8 & 0.97 \\
\hline & -7.3 & 60.8 & 2.3 & 1.1 & 4.1 & 1.8 & 0.5 & 836.3 & 0.7 & -0.25 & -214.1 & 0.82 \\
\hline 19 & -23.6 & 196.9 & 3.4 & 1.5 & 6.4 & 1.8 & 0.5 & 852.2 & 2.3 & -0.24 & -209.9 & 0.99 \\
\hline \multirow[t]{2}{*}{20} & -40.5 & 337.8 & 0.9 & 0.5 & 5.1 & 1.6 & 0.5 & 790.3 & 4.5 & -0.24 & -189.9 & 0.95 \\
\hline & -25.0 & 207.8 & 2.8 & 1.6 & 5.0 & 1.6 & 0.5 & 887.6 & 2.4 & -0.24 & -218.9 & 0.86 \\
\hline \multirow[t]{2}{*}{21} & -21.9 & 182.6 & 0.5 & 0.6 & 2.2 & 1.1 & 0.6 & 679.7 & 2.8 & -0.24 & -165.2 & 0.99 \\
\hline & -11.7 & 97.5 & 4.5 & 1.7 & 7.5 & 2.0 & 0.4 & 880.1 & 1.1 & -0.25 & -222.6 & 0.90 \\
\hline \multirow[t]{2}{*}{23} & -14.1 & 117.4 & 4.2 & 2.4 & 5 & 1.6 & 0.5 & 815.5 & 0.8 & -0.25 & -207.3 & 0.99 \\
\hline & -4.6 & 38.8 & 4 & 1.6 & 7.1 & 1.9 & 0.5 & 834.3 & 0.2 & -0.26 & -220.2 & 0.91 \\
\hline \multirow[t]{2}{*}{24} & -25.6 & 213.1 & 0.8 & 0.4 & 6.0 & 1.8 & 0.5 & 706.7 & 3.1 & -0.24 & -171.3 & 0.99 \\
\hline & -24.8 & 206.8 & 3.4 & 2.5 & 3.8 & 1.4 & 0.5 & 852.4 & 2.5 & -0.24 & -209.6 & 0.92 \\
\hline 25 & -27.4 & 227.8 & 2.8 & 1.7 & 4.7 & 1.6 & 0.5 & 831.7 & 2.8 & -0.24 & -203.5 & 0.84 \\
\hline
\end{tabular}

${ }^{a} D E$ :activation energy, ${ }^{b} \mathrm{~S}$ : asymmetry of the peak, ${ }^{c} \mathrm{n}$ : order of chemical reaction, ${ }^{\mathrm{d}} \mathrm{a}_{\mathrm{m}}$ : decomposed substance fraction at the moment of maximum development of reaction with $\left(T=T_{m}\right),{ }^{e} Z$ : collision factor $\left(s^{-1}\right),{ }^{f} \Delta S$ : entropy in $\mathrm{KJ} / \mathrm{mol},{ }^{g} \Delta \mathrm{H}$ : enthalpy in $\mathrm{KJ} / \mathrm{mol},{ }^{\mathrm{h}} \mathrm{R}^{2}$ : coefficient of determination.

groups exhibited slightly blue-shifted peaks (shift to a lower wavelength up to $7 \mathrm{~nm}$ ) at $341 \mathrm{~nm}$ and 338 $\mathrm{nm}$, respectively. Thus, no significant changes in the absorption spectra were noticed upon replacing the phenylene units by pyridine units in the macromolecular chain.

2. The blue emissions at $420 \mathrm{~nm}$ and $405 \mathrm{~nm}$ for the polyamide 18 derived from benzidine, attributed to the highly conjugation system, also blue-shifted (shifted to a lower wavelength) upon introducing flexible linkages such as ether bond in $\mathbf{2 0}$ (314 $\mathrm{nm}$ ), methylene group in $\mathbf{2 3}(336 \mathrm{~nm})$ or sulfone group in $24(344 \mathrm{~nm})$ in the polymeric chains.

3. Blue emission observed for benzidine-containing polyamide 18 containing $p$-acetoxy substituent $(407 \mathrm{~nm})$ was dramatically blue-shifted (shifted to a lower wavelength) (362 nm) for its analogue 19 containing $m$-acetoxy substituent. This result clearly demonstrated that methoxy group behaves differently depending upon how it is structurally oriented. Both the resonance $(+R)$ and inductive $(-I)$ effects of the $p$-acetoxy substituents account for the observed high wavelength emission in 18 while only inductive effect $(-I)$ of the $m$-acetoxy substituents account for relatively lower wavelength emission peak in 19.

\section{Thermal analysis}

The thermal properties of the prepared polymers were evaluated by differential thermo gravimetric (DTG) and differential thermal analysis (DTA) techniques. Thermal stability of the polymers was studied in the range $25^{\circ} \mathrm{C}-$ $700^{\circ} \mathrm{C}$ (char yield) and the results are complied in Tables 2 and 3 . Thermal results revealed that the polyamides $\mathbf{1 2}$, 14, 16, 18, 20 and 24 derived from the diacid chloride 10 demonstrated higher thermal stability compared to their partners 13, 15, 17, 19, 21 and 25, respectively, derived from the diacid chloride 11. All polymers exhibited an endothermic decomposition peaks in the range $80^{\circ} \mathrm{C}-$ $150^{\circ} \mathrm{C}$ correspond to a dehydration process while the major decomposition peaks appeared around $524^{\circ} \mathrm{C}-$ 
Table 5 Kinetic parameters of the polyhydrazides 31,32 and poly (1,3,4-oxadiazole-amide)s 33,34

\begin{tabular}{|c|c|c|c|c|c|c|c|c|c|c|c|c|}
\hline No & Slope DTA & $\Delta \mathrm{E}^{\mathrm{a}}$ & a & b & $\mathrm{S}^{\mathbf{b}}$ & $\mathrm{N}^{c}$ & $a_{m}^{d}$ & $\mathrm{~T}_{\mathrm{m}}(\mathrm{K})$ & $\mathrm{Z}^{\mathrm{e}}$ & $\Delta S^{f}$ & $\Delta \mathrm{H}^{\mathrm{g}}$ & ${ }^{h} R^{2}$ \\
\hline \multirow[t]{3}{*}{31} & -25.9 & 215.5 & 0.5 & 0.4 & 3.5 & 1.4 & 0.56 & 557.2 & 2.5 & -0.24 & -135.0 & 0.99 \\
\hline & -16.6 & 138.4 & 0.9 & 0.4 & 6.4 & 1.8 & 0.51 & 696.0 & 1.2 & -0.25 & -174.1 & 0.99 \\
\hline & -13.7 & 114.2 & 3.4 & 1.3 & 7.4 & 2.0 & 0.49 & 825.2 & 0.8 & -0.25 & -210.2 & 0.99 \\
\hline 32 & -19.7 & 164.3 & 4.3 & 2.3 & 5.3 & 1.7 & 0.52 & 853.9 & 1.1 & -0.25 & -215.3 & 0.99 \\
\hline \multirow[t]{2}{*}{33} & -2.4 & 19.9 & 0.5 & 1.6 & 0.8 & 0.7 & 0.69 & 357.1 & 0.34 & -0.25 & -91.1 & 0.90 \\
\hline & -12.9 & 107.8 & 4.6 & 1.4 & 9.3 & 2.2 & 0.47 & 849.9 & 0.77 & -0.25 & -217.3 & 0.88 \\
\hline 34 & -19.5 & 162.8 & 3.2 & 1.1 & 8.3 & 2.1 & 0.48 & 823.0 & 1.2 & -0.25 & -207.1 & 0.94 \\
\hline
\end{tabular}

${ }^{a} \Delta$ E:activation energy, ${ }^{b} \mathrm{~S}$ : asymmetry of the peak, ${ }^{c} n$ : order of chemical reaction, ${ }^{d} a_{m}$ : decomposed substance fraction at the moment of maximum development of reaction with $\left(T=T_{m}\right)$, ${ }^{e} \mathrm{Z}$ : collision factor $\left(\mathrm{s}^{-1}\right),{ }^{\mathrm{f}} \Delta \mathrm{S}$ : entropy in $\mathrm{KJ} / \mathrm{mol},{ }^{\mathrm{g}} \Delta \mathrm{H}$ : enthalpy in $\mathrm{KJ} / \mathrm{mol},{ }^{\mathrm{h}} \mathrm{R}^{2}$ : coefficient of determination.

$700^{\circ} \mathrm{C}$ which may be attributed to the cleavage of the amide bonds. Structure-thermal property correlation based on changing the diamine monomer, as a single structural modification, demonstrated an interesting connection between a single change and thermal properties. TG/DTG curves of the polymeric nanoparticles 12-24 are shown in Figures 4 and 5. Polyamides 14, derived from $m$-phenylenediamine, exhibited three endothermic decomposition peaks at $150^{\circ} \mathrm{C}, 286^{\circ} \mathrm{C}$ and $552^{\circ} \mathrm{C}$ leaving $17 \%$ of the polymer as remaining mass residue; while polyamide $\mathbf{1 6}$, derived from 2,6-diaminopyridine showed four exothermic decompositions peaks at $120^{\circ} \mathrm{C}, 200^{\circ} \mathrm{C}, 300^{\circ} \mathrm{C}$ and $590^{\circ} \mathrm{C}$, respectively, leaving $3.6 \%$ of the polymer as residue. This result clearly demonstrated the high thermal stability of 14 relative to its analogues 16. Polyamides 18, 20, 24 exhibited major degradation processes at $560^{\circ} \mathrm{C}, 614^{\circ} \mathrm{C}$ and $584^{\circ} \mathrm{C}$ leaving $11.9 \%, 3.9 \%$ and $6.0 \%$ of the polymers, respectively, as char yields. Similarly, polyamides 19, 21, 25 exhibited major degradation processes at $578^{\circ} \mathrm{C}, 605^{\circ} \mathrm{C}$ and $556^{\circ} \mathrm{C}$ leaving $6.9 \%, 8.1 \%$ and $8.3 \%$ char yields.

Polyhydrazide 31 exhibited three degradation processes at $130^{\circ} \mathrm{C}, 308^{\circ} \mathrm{C}$ and $549^{\circ} \mathrm{C}$, respectively, leaving $7.6 \%$ char yields while degradation processes of the polymer 32 occurred at $130^{\circ} \mathrm{C}, 334^{\circ} \mathrm{C}, 574^{\circ} \mathrm{C}$, respectively, and only $1.6 \%$ of the polymer was the remaining residue. Interestingly, polyhydrazides 31 and $\mathbf{3 2}$ exhibited second stages weight losses $15.35 \%$ at $308^{\circ} \mathrm{C}$ and $35.36 \%$ at $334^{\circ} \mathrm{C}$, respectively, attributed to the loss of the terminal OAc and dehydrative cyclization $(15.70 \%)$ in case of $\mathbf{3 1}$ while debloking of the pendant group $(35.38 \%)$ in case of polymer 32 . These results clearly proved that the polyhydrazide $\mathbf{3 1}$ derived from the diacid chloride $\mathbf{1 0}$ exhibited higher thermal stability compared to its partner $\mathbf{3 2}$ derived from the diacid chloride 11. TG/DTG curves of the polymeric nanoparticles 31-34 are shown in Figure 6.

Char yield can be used as criteria for evaluating limiting oxygen index (LOI) of the polymers in accordance with Van Krevelen and Hoftyzer equation [32]. LOI $=17$ $+0.4 \mathrm{CR}$ where $\mathrm{CR}=$ char yield. The LOI values of all polymers calculated based on their char yield at $700^{\circ} \mathrm{C}$ were less than 28. On the basis of LOI values, such macromolecules cannot be classified as self-extinguishing polymers.

The thermodynamic parameters of decomposition processes of polymers, namely, activation energy $\Delta E$ enthalpy $(\Delta H)$, entropy $(\Delta S)$ were evaluated by employing the Horowitz-Metzger equation [33], Tables 4 and 5. The order of chemical reactions (n) was calculated via the peak symmetry method by Kissinger [27]. The asymmetry of the peak, $S$, is calculated as follows:

$$
\begin{aligned}
& S=0.63 n^{2} \\
& n=1.26(a / b)^{1 / 2}
\end{aligned}
$$

The value of the decomposed substance fraction, $\alpha_{m}$, at the moment of maximum development of reaction (with $\mathrm{T}=\mathrm{Tm}$ ) being determined from the relation (3) [34]:

$$
\left(1-\alpha_{m}\right)=n^{1 / 1-n}
$$

The values of collision factor, $\mathrm{Z}$, can be obtained in case of Horowitz Metzger by making the use of the relation (4) [35]:

$$
Z=\frac{E}{R T_{m}} \phi \exp \left(\frac{E}{R T 2_{m}}\right)=\frac{K T_{m}}{h} \exp \left(\frac{\Delta S^{\#}}{R}\right)
$$

where $\Delta S^{\#}$ is the entropies of activation, $\mathrm{R}$ represents molar gas constant, $\phi$ rate of heating $\left(\mathrm{K} \mathrm{s}^{-1}\right), \mathrm{K}$ the Boltzmann constant, and $h$ the Planck's constant [36]. The change in enthalpy $(\Delta \mathrm{H})$ for any phase transformation [37] taking place at any peak temperature, Tm, can be given by the following equation: $\Delta S=\Delta H / T_{m}$. Based on least square calculations, the Ln $\Delta \mathrm{T}$ versus $1000 / \mathrm{T}$ plots for all complexes, for each DTA curve, gave straight lines from which the activation energies were calculated according to the reported methods [38]. The slope is of Arrhenius type and equals to $-E / R$.

The kinetic data obtained from the nonisothermal decomposition of the prepared polyamides 12-25 are 
given in Table 2. Some trends and conclusions may be achieved as follows:

1 - The calculated values of the collision number, $Z$, showed a direct relation to $E_{\mathrm{a}}$. The maximum and minimum $Z$ values are 5.51 and 0.78 , respectively, to suggest different mechanisms with variable speeds. The values of the decomposed substance fraction, $\alpha_{m}$, at the maximum development of the reaction are of nearly the same magnitude and lie within the range 0.48-0.68. The maximum and the minimum $T_{\mathrm{m}}$ values are $887 \mathrm{~K}$ and $823 \mathrm{~K}$, respectively.

2- The change of entropy values, $\Delta S$, for all complexes are nearly of the same magnitude and lie within the range 0.23 to $-0.26 \mathrm{~kJ} \mathrm{~K}^{-1} \mathrm{~mol}^{-1}$, all are with -ve signs. Therefore, the transition states are more ordered, i.e., in a less random molecular configuration than the reacting complexes. The fractions appearded in the calculated order of the thermal reactions, $n$, Table 4 , confirmed that the reactions proceeded in complicated mechanisms.

3- Activation energies values $(\Delta E)$ of polyamides 12, 14, 16, 18, 20 and 24 derived from the diacid chloride 10 demonstrated lower $\Delta E$ values compared to their partners 13, 15, 17, 19, 21 and 25, respectively, derived from the diacid chloride 11. Noteworthy mentioning that sulfone-containing polymer 24, 25 exhibited higher $\Delta \mathrm{E}$ than their ether-containing polymers analogs 20, 21, respectively, and the first and second decomposition steps in some polymers and have nearly equal $\Delta \mathrm{E}$ values, indicating similar degradation mechanism in both compounds. From the $\Delta \mathrm{E}$ values, one can concluded that the water molecules are easily eliminated from all ligands and the energies of activation for the second stages of decomposition are higher than that of the first stage.

4- The enthalpy $(\Delta H)$ of polyamides $12,14,16,18,20$ and 24 derived from the diacid chloride 10 demonstrated higher values compared to their partners 13, 15, 17, 19, 21 and 25, respectively, derived from the diacid chloride 11 and the negative values of $\Delta H$ means that the decomposition processes are exothermic.

5 - The collision number $Z$ values of the polyhydrazides 31, 32 and their corresponding poly (1,3,4-oxadiazole) 33 and 34, Table 3 , are 0.84 and $1.19,0.77$ and 1.22, respectively, suggesting similar mechanisms. The values of the decomposed substance fraction, $\alpha_{\mathrm{m}}$, at the maximum development of the reaction are of nearly the same magnitude and lie within the range 0.48-0.52. The maximum and the minimum $T_{\mathrm{m}}$ values are $849 \mathrm{~K}$ and $823 \mathrm{~K}$, respectively. Activation energies values $(\Delta E)$ of polyamides 32 and 34 demonstrated higher $\Delta E$ values compared to their partners $\mathbf{3 1}$ and 33, respectively. The enthalpy $(\Delta H)$ of polyamides $31-34$ were $-210 \mathrm{kjmol}^{-1}$, $-215 \mathrm{kjmol}^{-1}, 217 \mathrm{kjmol}^{-1}$ and $207 \mathrm{kj} \mathrm{mol}^{-1}$, respectively, and the decomposition processes are exothermic.

\section{Conclusions}

A series of aromatic polyamides nanoparticles with pendant structures comprised of $m$ - and $p$-acetoxybenzamide groups were synthesized by solution polycondensation of 5-(4-acetoxybenzamido)isophthaloyl chloride or 5-(3-acetoxybenzamido)isophthaloyl chloride with commercially available aromatic diamines. In addition, two new poly (amide-1,3,4-oxadiazole)s were prepared via dehydrative cyclization of the copolyhydrazides derived from polycondensation of the readily accessible 5-(4-acetoxybenzoylamino) isophthalohydrazide or 5-(3-acetoxybenzoylamino) isophthalohydrazide, respectively, with isopthaloyl chloride. The thermal behavior of all polymers exhibited two major thermal decompositions at about $300^{\circ} \mathrm{C}$, due to the breakage of the acetoxy group in the lateral chain, and at around $524^{\circ} \mathrm{C}-700^{\circ} \mathrm{C}$, which may be attributed to the cleavage of the main amide bonds. Structure- photoluminescence correlation based on changing the diamine monomer, as a single structural modification, demonstrated an interesting connection between a single change and optical and fluorescence emission properties. The blue emissions at $420 \mathrm{~nm}$ and $405 \mathrm{~nm}$ for the polyamide derived from benzidine, attributed to the highly conjugation system, was blue-shifted (shifted to a lower frequency) compared with that of polyamides containing flexible linkages. The prepared polymers could be dissolved in polar aprotic solvents at room temperature or upon heating. Further investigations to obtain films with reasonably good mechanical properties for different applications are in progress.

\section{Competing interests}

The authors declare that they have no competing interests.

\section{Authors' contributions}

$\mathrm{HHAMH}$ and EMEM initiating the research point and monitored the experimental work, acquisition of data, analysis and interpretation of data and wrote draft the manuscript and gave final approval of the version to be published. AFEH carried out the thermal studies, acquisition of data, analysis and interpretation of data and helped to draft the manuscript. YAEK carried out the synthesis of monomers and polymers. All authors read and approved the final manuscript.

Authors' information

Part of M.Sc thesis of Y. M. A. Elkony.

Received: 14 November 2012 Accepted: 16 January 2013 Published: 23 January 2013

\section{References}

1. Garcia JM, Garcia FC, Serna F, de la Pena JL: High performance polyamides. Prog Polym Sci 2010, 35:623.

2. Trigo-Lopez M, Estévez P, San-José N, Gomez-Valdemoro A, Garcia FC, Serna F, de la Pena JL: Recent patents on aromatic polyamides. Recent Patents Mater Sci 2009, 2:190.

3. Gallini J: Polyamides aromatic. Encyclopedia of polymer science and technology. New York: John Wiley \& Sons; 2005:3:558.

4. Uthirakumar P, Hong CH, Suh EK, Lee SY: Novel fluorescent polymer/zinc oxide hybrid particles: synthesis and application as a luminescence converter for white light-emitting diodes. Chem Mater 2006, 18:4990.

5. Hsiao SH, Liou GS, Wang HM: Highly Stable electrochromic polyamides based on N, N-Bis(4-aminophenyl)-N', N'-bis(4-tert-butylphenyl)-1,4phenylenediamine. J Polym Sci Part A: Polym Chem 2009, 47:2330. 
6. Liou GS, Lin KH: Synthesis and characterization of a novel electrochromic aromatic polyamide from $\mathrm{AB}$-type triphenylamine-based monomer. J Polym Sci Part A: Polym Chem 1988, 2009:47.

7. Yen HJ, Liou GS: Novel thermally stable triarylamine-containing aromatic chromophores for highly efficient green light emitting materials. J Polym Sci Part A: Polym Chem 2008, 46:7354.

8. Nechifor M: Synthesis and properties of some aromatic polyamides with coumarin chromophores. React Funct Polym 2009, 69:27.

9. Martinez-Manez R, Sancenon F: Fluorogenic and chromogenic chemosensors and reagents for anions. Chem Rev 2003, 103:4419.

10. Martinez-Manez R, Sancenon F: New advances in fluorogenic anion chemosensors. J Fluoresc 2005, 15:267.

11. Sava I, losip MD, Bruma M, Hamciuc C, Robison J, Okrasa L, Pakula T: Aromatic polyamides with pendent acetoxybenzamide groups and thin films made therefrom. Eur Polym J 2003, 39:725.

12. In I, Kim SY: Soluble wholly aromatic polyamides containing unsymmetrical pyridyl ether linkages. Polymer 2006, 47:547.

13. Mehdipour-Ataei $\mathrm{S}$, Heidari $\mathrm{H}$ : Synthesis and characterization of novel soluble and thermally stable polyamides based on pyridine monomer. Macromol Symp 2003, 193:159.

14. Tan J, Wang C, Peng W, Li G, Jiang JM: Synthesis, characterization, and properties of novel aromatic polyamides containing phthalazinone moiety. Polym Bull 2009, 62:195.

15. Schulz B, Bruma M, Brehmer L: Poly(1,3,4-oxadiazole)s as advanced materials. Adv Mater 1997, 9:601.

16. Schulz B, Brehmer L: Poly(arylene-1,3,4-oxadiazole)s. In Polymeric materials encyclopedia. Edited by Salamone J. Boca Raton, FL: CRC Press; 1996:7: 5595.

17. Kim SW, Shim SC, Jung BJ, Shim HK: Synthesis and properties of new electroluminescent polymers possessing both hole and electrontransporting units in the main chain. Polymer 2002, 43:4297.

18. Hsiao SH, Liou GS: A New Class of Aromatic Poly(1,3,4-oxadiazole)s and Poly(amide-1,3,4-oxadiazole)s Containing (Naphthalenedioxy) diphenylene Groups. Polymer J 2002, 34:917.

19. Hassan HHMA, Elhusseiny AF, Sweyllam AM: Synthesis of novel semiconducting aromatic polyesteramides containing pyridine: Characterization of nanometer-sized rod-like analogues and their copper (II) complexes. J Macromol Sci Part A 2010, 47:521.

20. Hassan HHAM, Elhusseiny AF, Sweyllam AM: Synthesis and properties of narrow-sized spherical aramides nanoparticles containing pyridine and their copper(II) complexes. J Macromo/ Sci Part A 2011, 48:73.

21. Hassan HHAM, Elhusseiny AF, Sweyllam AM: Polyamides nanoparticle containing flexible linkages and their copper complexes with novel dielectric properties structure property relationship. J Mol Str 2011, 1001:89.

22. Hassan HHAM, Elhusseiny AF, Sweyllam AM, Linhardt RJ: New sulfonated aramide nanoparticles and their copper complexes with anomalous dielectric behavior. J Appl Polym Sci 2012, 124. doi:10.1002/app.36791.

23. Hassan HHAM, El-Banna SG, Elhusseiny AF, Mansour EME: Antioxidant activity of new aramide nanoparticles containing redox-active $\mathrm{N}$ phthaloylValine moieties in the hepatic cytochrome $\mathrm{P}_{450}$ system in male rats. Molecules 2012, 17:8255.

24. Fessi H, Puisieux F, Devissaguet JP, Ammoury N, Benita S: Nano-capsule formation by interfacial deposition following solvent displacement. Int J Pharm 1989, 55:1.

25. Limayem I, Charcosset C, Sfar S, Fessi H: Preparation and characterization of spironolactoneloaded nanocapsules for paediatric use. Int J Pharm 2006, 325:124

26. Ferranti V, Marchais H, Chabenat C, Orecchioni AM, Lafont O: Caprolactone nanocapsules: incorporation efficiency and in vitro release profiles. Int J Pharm 1999, 193:107.

27. Lince F, Marchisio DL, Barresi AA: Strategies to control the particle size distribution of poly-caprolactone nanoparticles for pharmaceutical application. J Colloid Interface Sci 2008, 322:505.

28. Archer EA, Gong H, Krische MJ: Hydrogen bonding in noncovalent synthesis: selectivity and directional organization of molecular strands. Tetrahedron 2001, 57:1139.

29. Krische MJ, Lehn JM: Utilization of persistent hydrogen-bonding motifs in the self-assembly of supramolecular architectures. Struct Bond 2000, 94:3.

30. Sinigersky V, Wegner G, Schopov I: Synthesis and properties of polyphenylene vinylene containing 1,3,4-oxadiazole rings. Eur Polym $J$ 1993, 29:617.
31. Sava I, Bruma M, Szesztay M, Muller P: Poly(1,3,4-oxadiazole amideester)s and thin films made from them. High Perform Polym 2005, 17:263-275.

32. Van Krevelen DW, Hoftyzer PJ: Properties of Polymers. Their Estimation and Correlation with Chemical Structure. 3rd edition. New York: Elsevier; 1976.

33. Horowitz HH, Metzger $\mathrm{G}$ : A new analysis of thermogravimetric traces. Anal Chem 1963, 35:1464.

34. Kissinger E: Reaction kinetics in differential thermal analysis. Anal Chem 1957, 29:1702.

35. Oswald HR, Dubler E: In Thermal analysis. Edited by Wiedemann HG. Basel Switzerland: Birkhauser; 1972:2.

36. Horowitz $\mathrm{H}$, Metzer $\mathrm{G}$ : A new analysis of thermogravimetric traces. Anal Chem 1963, 35:1464.

37. Dhar $\mathrm{ML}$, Singh $\mathrm{O}$ : Kinetics and thermal decomposition of $\mathrm{Fe}(\mathrm{III})$ and $\mathrm{UO}_{2}$ (II) complexes with embelin (2,5-dihydroxy-3-undecyl-P-benzoquinone). J Therm Anal 1991, 37:259.

38. Traore $\mathrm{K}$ : Analyse thermique differentielle et cinetique de reaction III. Surface des pics d'analyse thermique differentielle et applications. J Therm Anal 1972, 4:135.

doi:10.1186/1752-153X-7-13

Cite this article as: Hassan et al:: Synthesis and characterization of thermally stable aromatic polyamides and poly(1,3,4-oxadiazole-amide)s nanoparticles containing pendant substituted bezamides. Chemistry Central Journal 2013 7:13.

Publish with ChemistryCentral and every
scientist can read your work free of charge
"Open access provides opportunities to our
colleagues in other parts of the globe, by allowing
anyone to view the content free of charge."
W. Jeffery Hurst, The Hershey Company.
- available free of charge to the entire scientific community
- peer reviewed and published immediately upon acceptance
- cited in PubMed and archived on PubMed Central
- yours - you keep the copyright
submit your manuscript here:
http://www.chemistrycentral.com/manuscript/

